\title{
Study of cytotoxic activity of Ti-13Nb-13Zr medical alloy with different surface finishing techniques
}

\author{
Viktoria Hoppe ${ }^{1, *}$ (1), Patrycja Szymczyk-Ziółkowska ${ }^{1}$, Małgorzata Rusińska ${ }^{1}$, \\ Dominik Poradowski ${ }^{2}$, Maciej Janeczek ${ }^{2}$, Grzegorz Ziółkowski ${ }^{1}$, and Bogdan Dybała ${ }^{1}$ \\ ${ }^{1}$ Politechnika Wroclawska, Wroclaw, Poland \\ ${ }^{2}$ The Faculty of Veterinary Medicine, Wroclaw University of Environmental and Life Sciences, Wroclaw, Poland
}

Received: 5 July 2021

Accepted: 11 August 2021

Published online:

20 August 2021

(C) The Author(s) 2021

\begin{abstract}
The characterization of materials surface is essential, as the initial in vivo response is highly dependent on surface properties. Surface topography is a key aspect that influences the response of cells to products resulting from interaction with the surface of a titanium alloy, including parameters such as adhesion, spread, migration, proliferation, and differentiation of cells. Various surface modifications are used to improve the interface properties between MC3T3 and NHDF cells and the Ti-13Nb-13Zr-based surface. Among the techniques discussed in this paper, scanning electron microscopy, laser confocal scanning microscopy, and computed tomography are adequate to investigate materials topography at different scale levels. Chemical characterization of the outer layers of $\mathrm{Ti}-13 \mathrm{Nb}-13 \mathrm{Zr}$ samples was performed with X-ray photoelectron spectrometry. Studies have shown that the surfaces resulting from the treatment enabling the formation of titanium oxide and zirconium oxide show the lowest cytotoxicity. Implants made from the new generation of titanium alloy, not containing toxic elements, with the use of surface modification could be an essential innovation in implantology.
\end{abstract}

\section{Introduction}

For new medical materials introduced to the market, it is necessary to verify their properties and impact on living organisms. The second generation of titanium alloys is becoming more popular for implant fabrication. One of the representatives of this group was developed by Davidson and Kovacs [1], the Ti$13 \mathrm{Nb}-13 \mathrm{Zr}$ ( $\beta$-rich $(\alpha+\beta)$-alloy), which represents all outstanding properties of titanium and its classic alloys but not containing aluminum, which is cytotoxic, and therefore promises safer biomedical applications. However, different aspects need to be

Handling Editor: Christopher Blanford.

Address correspondence to E-mail: viktoria.hoppe@pwr.edu.pl 
taken into account while assessing the suitability of Ti-13Nb-13Zr for implant fabrication. The implantation success depends on many factors, one of which is the ability to induce and support the creation of a stable connection with surrounding tissues. The research presented in this article focuses on analyzing the impact of surface modifications for the novel material, on surface characterization and its cytotoxic response.

The surface character of an implant is one of the most critical factors because it affects the process of osseointegration. It directly impacts the speed of bone growth and the mechanical nature of the boneimplant interface [2]. Developing a mechanism for immobilizing bone implants is nowadays one of the biggest challenges of implantology. Functional activity of cells on the implant surface, the quality of the implant surface, its properties (chemical, physical, and mechanical), as well as its topography, are some of the most relevant parameters in designing the implant surface [3-6]. The degree of roughness is important because of the bone metabolism: Rougher surfaces stimulate differentiation, growth, bone cell attachment, and increased mineralization. The total surface of biomechanical contact between tissue and implant can improve the osseointegration process and strengthen the connection between the implant and bone. Increased roughness, improved bioadhesion, and increased cell proliferation on the implant surface can be achieved by heat treatment, anodization, sandblasting, polishing, and the use of hydroxyapatite and antibacterial coatings [7].

Common mechanical surface modifications such as polishing, grinding, or grit blasting involve physical treatment by shaping and removing the top layer of the implant [8]. To obtain finer finishing degrees, the surfaces can be exposed to the smoothing process on the diamond, aluminide, or $\mathrm{SiC}$ abrasive using polishing clothes. Typical roughness values of smoothed surfaces are approximately $R_{a}=0.1 \mu \mathrm{m}$ for mirrorpolished surface and up to $R_{a}=1 \mu \mathrm{m}$ for rough finishing. During the smoothing of the surface, abrasive particles can be embedded into the metallic matrix and this phenomenon is called abrasive pollution [9]. The directional scratches created during the process are easily adhered to by early colonizers in the early step of biofilm formation because grooves can protect bacteria against shear forces and favor bacterial adhesion [10]. While grinding and polishing are used to achieve the desired surface finish, it should be understood that these methods will have a different effect on the condition of the surface. The mechanical modification will lead to plastic deformation and stresses in the surface area of the material. However, grinding and polishing are generally used as an intermediate step upstream to chemical, electrochemical, and other methods that will ultimately determine the properties of the modified surface [11].

The use of an aggressive liquid on the titanium substrate causes etching of depressions in the surface, resulting in a new surface layer with an increased thickness of titanium oxide. The acid etching methods generally are aimed to alter surface chemistry and micro-roughness and therefore influence the cell response. It is reported that nanotopography that allows bone ingrowth via acid etching on an implant may improve the roughness [12]. Pickling is a technical term for etching, mainly used to remove oxide deposits to obtain a clean and uniform surface finish [11]. Chemical modification alters the chemical properties of the carrier surface, causing specific interactions between cell surface molecules that not only affect the properties of the cell surface but also cause closely related changes to the inner structure and function of cells [13]. They are performed to remove oxide scales and contamination, aimed at improving biocompatibility and bioactivity [14-18].

One of the most effective methods of metal surface modification to improve its adhesive properties is sandblasting; therefore, it is used quite often in implant fabrication. This procedure not only alters the surface topography due to the treated microscale or nanoscale texture but also leaves the treated region in compressive residual stress, greatly improving not only mechanical fixation but also cellular differentiation $[19,20]$. The roughness value obtained during sandblasting depends on factors such as blasting material, particle size, and blasting pressure. For example, the average surface roughness in the range $0.5-1.5 \mu \mathrm{m}$ [21] or $2-6 \mu \mathrm{m}$ is obtained by the use of alumina particles in two different size ranges: 25-75 $\mu \mathrm{m}$ and 200-600 $\mu \mathrm{m}$, respectively [22]. From a biomedical point of view, for implants' descaling and surface roughening, the sandblasting method is the most popular [11]. The crucial problem in using sandblasting is the deposition of contaminant elements on the surface of the implant, which is caused using abrasive media [23]. Together with the nonuniform surface, the sandblasting method might not be effective enough to achieve early proliferation 
and bone formation, resulting in low quality of boneimplant bond [24-26].

A process consisting of two steps that complement each other in order: sandblasting with large grit and acid etching (SLA), is currently the most popular surface treatment of implants to produce the optimal surface for osseointegration [27-29]. This method aims to cause surface erosion as an outcome of a strong acid application on the previously blasted surface [28]. Micropits and sharp peaks formed on the surface after this combined treatment are known to promote osteoblast proliferation and bone formation $[27,28]$. SLA is considered a trustworthy modification to achieve an excellent rough titanium surface with suitable topography and roughness [27]. It can remove the surface contaminants, and the morphologic irregularities could improve initial cell anchorage, providing better osseointegration [17].

Another type of surface modification technique that allows changing the morphology and structure of the surface and contributes to the surface properties alteration in a wide range is electron beam treatment and coating deposition. Different physical and biomechanical properties are achieved by processing materials with the pulsed melting process that uses low-energy (up to $40 \mathrm{keV}$ ) and high-current electron beams (up to $40 \mathrm{~J} / \mathrm{cm} 2$ ). These swift changes are responsible for the quenching of the surface layers from the liquid state and affect the structural phase state in the surface layers of the material, where nonequilibrium structure-phase states are formed $[30,31]$. Moreover, coatings such as diamond-like carbon (DLC) have been proved to be valuable in medical applications as they provide unique mechanical, tribological, and biomedical properties [32]. Coating titanium alloys not only increases biocompatibility to the human biological environment but also reduces inflammatory reactions. Minimizing the direct contact of metal particles such as aluminum and vanadium ions entering adjacent tissues provided by coating techniques influences the survivor rate of blood cells that are in contact with implants [33], providing possibility for tissue regeneration. Film deposition also enhances the adhesion of cells, such as $\mathrm{CN}_{0.25}$ coating was proven to provide better adhesion and metabolic activity of bone marrow cells on titanium implants [34]. The microscopic surface properties affect the tendency to colonize specific cell groups-fibroblasts tend to colonize a smoother surface than osteoblasts, which are more common on rough surfaces [35]. In contrast, porous coatings on implants require active bone involvement in implant fixation. [36, 37]. Higher roughness of the titanium surface would favor the early bacterial infections caused by biofilm formation. Researchers in [38] found that surface modifications of Ti-based alloys influence not only the material properties but also their biological attributes such as protein adhesion, cell growth, cell proliferation, and antibacterial activity [39]. However, as the biofilm became mature, the influence of surface roughness was diminished in a bacterial species-dependent manner. Both functional and histomorphometric assays indicate that bacterial contamination has a negative impact on osseointegration, especially for rough surfaces [40].

The MTT (3-[4,5-dimethylthiazol-2-yl]-2,5 diphenyl tetrazolium bromide) assay is a frequently used method for evaluating cell metabolic activity. Losing the ability to convert MTT into formazan during cell dying, color formation serves as a convenient marker of viable cells. MTT assay is actually measuring mitochondrial activity [41].

Numerous studies have investigated the correlation between surface finishing and tissue reactions for the first generation of titanium alloys. This paper presents new results obtained for the second-generation $\mathrm{Ti}-$ $13 \mathrm{Nb}-13 \mathrm{Zr}$ treated with five different surface treatment techniques with regard to the biological reactions.

\section{Materials and methods}

\section{Surface modification}

The material Ti-13Nb-13Zr (Shaanxi Yunzhong Industry Development Co., Baoji City, China) in the form of pellets with a diameter of $9 \mathrm{~mm}$ and $14 \mathrm{~mm}$ and thickness $2 \mathrm{~mm}$ was used for the tests. These pellets were subjected to the surface modifications described in Table 1.

Prior to each modification of the surface, the samples were cleaned in an ultrasonic cleaner, using an isopropanol bath, to remove surface contaminants and degrease them.

\section{Microscopic examination}

Surface microscopic examinations after surface modifications were carried out using light microscopy and scanning electron microscopy. 
Table 1 Surface modification parameter table

\begin{tabular}{|c|c|c|c|}
\hline Type & Modificator & Parameters & Time \\
\hline Grinding & $\# 1000 \mathrm{SiC}$ abrasive & $300 \mathrm{rpm}$ & $120 \mathrm{~s}$ \\
\hline Polishing & $\mathrm{SiO}_{2}$ suspension and polishing cloth & $50 \mathrm{rpm}$ & $1000 \mathrm{~s}$ \\
\hline Sandblasting & $\mathrm{Al}_{2} \mathrm{O}_{3} \# \mathrm{~F} 120$ & $\begin{array}{l}p=3 \mathrm{bar} \\
\varphi^{*}=90^{\circ} \\
l^{* *}=50 \mathrm{~mm}\end{array}$ & $30 \mathrm{~s}$ \\
\hline Chemical etching & $\begin{array}{l}\mathrm{HF}+\mathrm{HNO}_{3} \\
\text { (Kroll reagent) }\end{array}$ & room temperature & $240 \mathrm{~s}$ \\
\hline SLA & $\begin{array}{l}\mathrm{AL}_{2} \mathrm{O} 3 \text { and } \\
4 \% \mathrm{HF} \text { in } \mathrm{H}_{2} \mathrm{O}_{2} \text { solution }\end{array}$ & $\begin{array}{l}p=2.5 \mathrm{MPa} \\
\varphi^{*}=90^{\circ} \\
l^{* *}=50 \mathrm{~mm} \text { room temperature }\end{array}$ & $30 s+240 s$ \\
\hline
\end{tabular}

\footnotetext{
*Angle to the plane of the sample

** Distance between the nozzle and the sample
}

To evaluate the surface changes after the modification processes, the scanning electron microscope Zeiss EVO MA25 (Carl Zeiss, Oberkochen, Germany) was used.

\section{Surface topography}

To assess the surface in the macroscale, the digital microscope Keyence VHX-600 was used (Keyence, Osaka, Japan). In addition, linear and the surface roughness parameters $\left(R_{z}, R_{q}\right.$, and $R_{a}$ and also $S_{z}, S_{q}$ and $S_{a}$ ) were designated using a laser confocal scanning microscope LEXT OLS4000 (Olympus, Tokyo, Japan). According to the following standards: ISO 25178 [42] and ISO 4287 [43], linear and surface roughness parameters $\left(R_{z}, R_{q}, R_{a}, S_{z}, S_{q}\right.$, and $\left.S_{a}\right)$ were measured. Vertical parameters include the heights of peak and pit depths and surface profile, and its representative was $R_{z}$ determined as the roughness height according to ten points. The amplitude parameters that relate to the mean ordinate values include $R_{a}$, which is the arithmetic mean deviation of the roughness profile. The $R_{q}$ parameter is generally related to the $R_{a}$ parameter, and the $R_{q}$ parameter value is greater than the value of the $R_{a}$ parameter (for random profiles by about 25\%) and is defined as the mean square deviation of the surface roughness is the root mean square value of the deviation of the surface roughness within the sample area. According to the definitions, $S_{z}$ is the sum of the maximum peak height value and the maximum pit height value within a defined area, $S_{a}$ is the arithmetic mean of the absolute of the ordinate values, and the related $S_{q}$ parameter is the root mean square value of the ordinate values on a reference plane.

Areal surface texture analysis was performed using a computed tomography (CT) device Phoenix vltome Ix (General Electric, Frankfurt, Germany). All CT measurements were performed at the resolution of $9.14 \mu \mathrm{m}$ and magnification of $21.86 \times$. The tube voltage was kept constant for all scans at $200 \mathrm{kV}$, the current at $40 \mathrm{~mA}$, and a copper filter of $0.5 \mathrm{~mm}$ thickness was put between the X-ray source and the sample. Based on CT reconstruction, qualitative analysis of pellets' surface topography was performed using VG Studio Max 3.0 (Volume Graphics, Heidelberg, Germany) for local advanced surface determination.

The development of the surface of individual samples (Fig. 1) was compared to the nominal surfaces and the reference radius with the value $R=4.45$ [mm].

\section{Contact angle}

The water contact angle of the obtained materials was measured using an OEG Surftens Universal (OEG, Frankfurt, Germany) goniometer with integrated Surftens 47 software using the sitting drop method. At least ten measuring points were made for every type of sample. The water droplet size was $3.9 \mu$. Immediately after planting the drops, photographs were taken, the shape and volume of the drops were analyzed, and the contact angle was measured. 

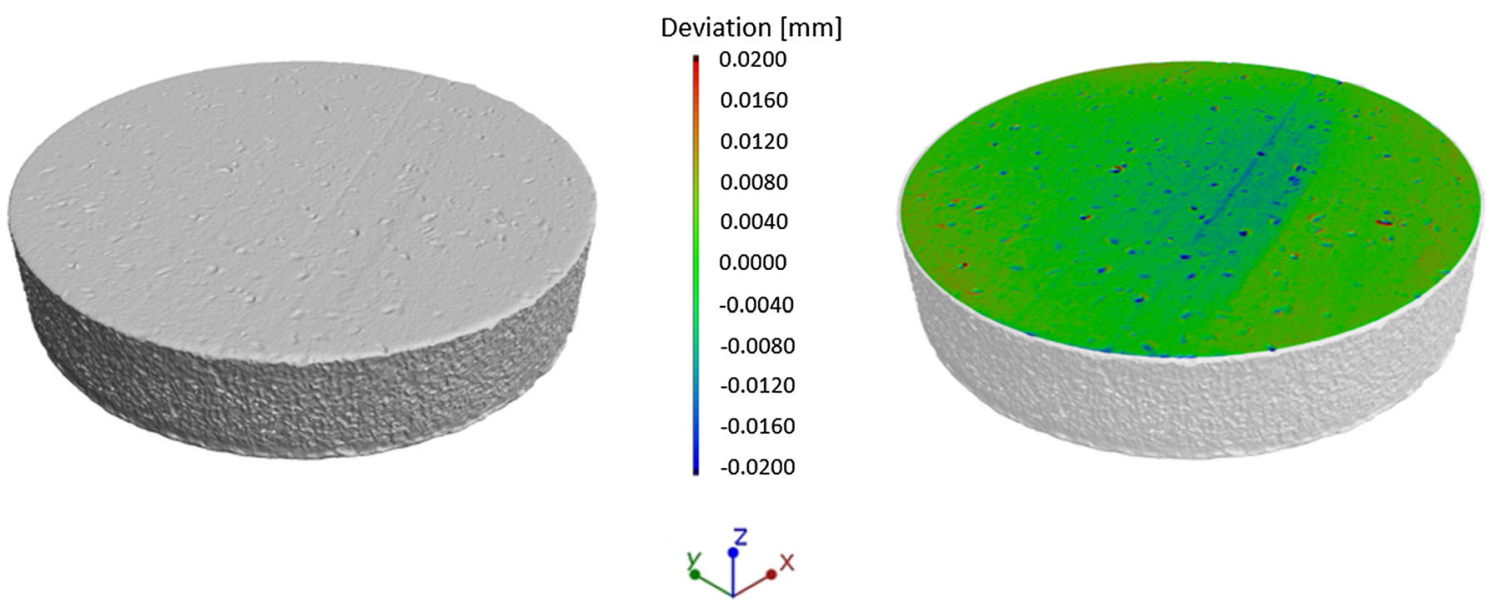

Figure 1 Image of the analyzed surface with the use of CT reconstruction.

\section{XPS}

X-ray photoelectron spectroscopy (XPS) was performed with a Kratos Axis Supra (Kratos, Manchester, UK) spectrometer, equipped with a monochromatic $\mathrm{Al} \mathrm{K} \alpha$ radiation $(1486.7 \mathrm{eV})$ source. The instrument was calibrated to give a $\mathrm{BE}$ of $84.0 \mathrm{eV} \pm 0.1 \mathrm{eV}$ for the $4 \mathrm{f} 7 / 2$ line of metallic $\mathrm{Au}$, the dispersion adjusted to give a $\mathrm{BE}$ of $932.62 \mathrm{eV}$ for the $\mathrm{Cu} 2 \mathrm{p} 3 / 2$ line of metallic $\mathrm{Cu}$. The energy resolution was examined on silver samples. Survey (wide) spectra were gathered with a quality corresponding to the full width at half maximum (FWHM) parameter for $\mathrm{Ag} 3 \mathrm{~d}$ line equal to $0.71 \mathrm{eV}$ at an energy step size of $0.5 \mathrm{eV}$. For high-resolution spectra, the FWHM parameter for $\mathrm{Ag} 3 \mathrm{~d}$ line was equal to $0.58 \mathrm{eV}$ at the step size: $0.1 \mathrm{eV}$. The peaks fitting was conducted using CasaXPS software version 2.3.18 on a Shirley background.

\section{Microbiological tests}

Cytotoxic effects were assessed after $24 \mathrm{~h}$ of direct cell contact with the tested extracts. Morphological changes of fibroblasts were assessed using the system imaging of EVOS FLoid cells (Thermo Fisher, Waltham, MA, USA), and a test was chosen to assess survival colorimetric MTT ((3-(4,5-dimethylthiazol-2yl)-2,5-diphenyltetrazolium bromide) type in accordance with Annex C PN-EN ISO 10993-5: 2009. Culture of NHDF (normal human dermal fibroblast) (ATCC-American Type Culture Collection) cells and culture of MC3T3-E1 (osteoblast precursor cell line) (ATCC) cells were carried out in DMEM
(Dulbecco's modified Eagle medium) with $4.5 \mathrm{~g} / 1$ D-glucose, with the addition of $1 \% 4 \mathrm{nM}$ L-glutamine (Lonza, Basel, Switzerland), with 2\% $100 \mathrm{U} / \mathrm{ml}$ streptomycin and $100 \mu \mathrm{g} / \mathrm{ml}$ penicillin (SigmaAldrich, Saint Louis, MO, USA) and 10\% fetal bovine serum (Sigma-Aldrich, Saint Louis, MO, USA). The culture was carried out in a SafeGrow Pro incubator (EuroClone, Pero, Italy) with a constant concentration of $5 \% \mathrm{CO}_{2}$, at $37{ }^{\circ} \mathrm{C}$ and constant humidity. The doubling time, DT, for most of the above cells line was around $24 \mathrm{~h}$. After 24-h culture, test compounds were added to the defined wells of the microplate and incubated in a CO2 incubator for $24 \mathrm{~h}$, after which the monolayer medium was removed, and cells were washed twice with sterile PBS (phosphatebuffered saline) solution, and microtiter plates into the wells fresh culture medium was added. After $48 \mathrm{~h}$ of cell culture, the test was performed using MTT. $50 \mu \mathrm{L}$ tetrazole salt solution (concentration was added to each well of the microplate) $0.05 \mathrm{mg} / \mathrm{ml}$ final. The microplate was placed for 3-4 h (depending on the cellular line) in a $\mathrm{CO}_{2}$ incubator. After incubation, microplates were added to the wells with $100 \mu 1$ DMSO (dimethyl sulfoxide) each to dissolve the violet living cells formed in the environment formazan crystals. The absorbance of the formazan solution (gently mixed) was read at wavelength $\lambda=570 \mathrm{~nm}$ and reference wavelength $\lambda=720 \mathrm{~nm}$. Next, the contents of each well were mixed and the plate was placed in a Multiskan GO spectrophotometer (ThermoFisher, Waltham, MA, USA), and the absorbance was read at $570 \mathrm{~nm}$ for each sample. The percentage of live cells was computed by comparing the absorbance value of the test samples with the 
control absorbance value (cells not treated with compounds). The cell viability for both assays was calculated as $[(x-y) /(z-y)] \times 100 \%$, where $x, y$, and $z$ were the average absorbance of cells treated with the extract, the average absorbance of the blank medium, and the average absorbance of cell control, respectively. The control absorbance was taken as $100 \%$. An untreated cell culture was used as the negative control. The positive control was performed by using a strong cytostatic drug-doxorubicin.

\section{Results}

\section{Microscopic examination}

In the case of ground surfaces, there are noticeable lines and deeper scratches originating from the abrasive material, whose direction is in accordance with the direction of abrasive machining. The surface observed using a light microscope is morphologically similar to the surface observed using the scanning electron microscope (Fig. 2).

The polished surface is characterized by the lack of surface development-it is smooth with locally gently visible alloy microstructure. The surface after sandblasting has a developed surface, numerous craters, and abrasive cavities. The SEM microscopic image reveals the remains of the abrasive on its surface (darker areas corresponding to the $\mathrm{Al} 2 \mathrm{O} 3$ particles embedded in the surface). The surface after chemical etching is characterized by a clearly darker surface than the others, and the SEM image shows pits indicating local dissolution of the surface by the chemical reagent. This is confirmed by SEM images at higher magnifications-the remains of the primary surface layer and the revealed microstructure of the alloy are visible. The surface after SLA is characterized by a glossy surface with visible areas corresponding to individual grains in the material (visible grain boundaries in the SEM image).

\section{Surface topography}

Laser scanning confocal microscopy (LCSM) eliminates the effect of the upper or lower planes, in epifluorescence or in reflection. Compared to traditional microscopy, confocal microscopy with laser scanning allows obtaining the increased spatial and axial resolution and perfectly superposable images as a series of optical cross sections, where the potential for 3D visualization, reconstruction, and quantification is enormous.

Thanks to the use of LCSM, the following parameters characterizing the geometric structure of the surface in a $2 \mathrm{D}$ system were measured [44]:

- $R_{a}$-arithmetic mean deviation of the roughness profile, used as a global evaluation of the roughness amplitude.

- $R_{z}$-roughness height according to ten points, usually used to check whether the profile has protruding peaks that might affect the static or sliding contact function.

- $R_{q}$-the mean square deviation of the profile, the root mean square value of the deviation of the surface roughness within the sample area, related to the $R_{a}$ parameter.

The geometrical structure of the surface has been characterized in 3D using parameters:

- $S_{a}$-arithmetic mean deviation of the height of surface unevenness from the reference plane.

- $S_{z}$-the maximum height of the 3D profile.

- $S_{q}$-the mean square deviation of the height of surface unevenness from the reference plane.

It was observed that the sandblasted surfaces were characterized by the highest values of the linear parameters $R_{z}, R_{a}$, and $\mathrm{R}_{\mathrm{q}}$, which testifies to a large variation in the height of individual points participating in the profile. For sandblasted surfaces, it is $R_{z}=63.24 \mu \mathrm{m}, R_{a}=6.24 \mu \mathrm{m}$, and $R_{q}=8.08 \mu \mathrm{m}$. Slightly lower values are observed in the case of surfaces after chemical etching in the case of the $R_{z-}$ $=56.44 \mu \mathrm{m}$ parameter, however, with a twofold decrease in the values of $R_{q}$ and $R_{a}$ in relation to the sandblasted surface. Intermediate values of the parameters are observed for the surface after SLA treatment and take the following values: $R_{z-}$ $=40.43 \mu \mathrm{m}, R_{q}=4.00 \mu \mathrm{m}$, and $R_{a}=2.92 \mu \mathrm{m}$. The lowest values of linear roughness parameters are observed for surfaces after grinding and polishing, for which they assume the following values: $R_{z-}$ $=16.70 \mu \mathrm{m}, R_{q}=2.27 \mu \mathrm{m}$, and $R_{a}=1.64 \mu \mathrm{m}$ for ground and $R_{z}=2.68 \mu \mathrm{m}, R_{q}=0.45 \mu \mathrm{m}$, and $R_{a-}$ $=0.24 \mu \mathrm{m}$ for polished surfaces. Detailed data are shown in Fig. 3. The same applies to the surface $S_{z \prime}$ $S_{q}$, and $S_{a}$ parameters. The highest values of the $S_{z}$ parameter are observed for the sandblasted and chemically etched surfaces, and they are 
Figure 2 Images of the surface after various surface modifications obtained with the use of light microscopy (a) and scanning electron microscopy (b).

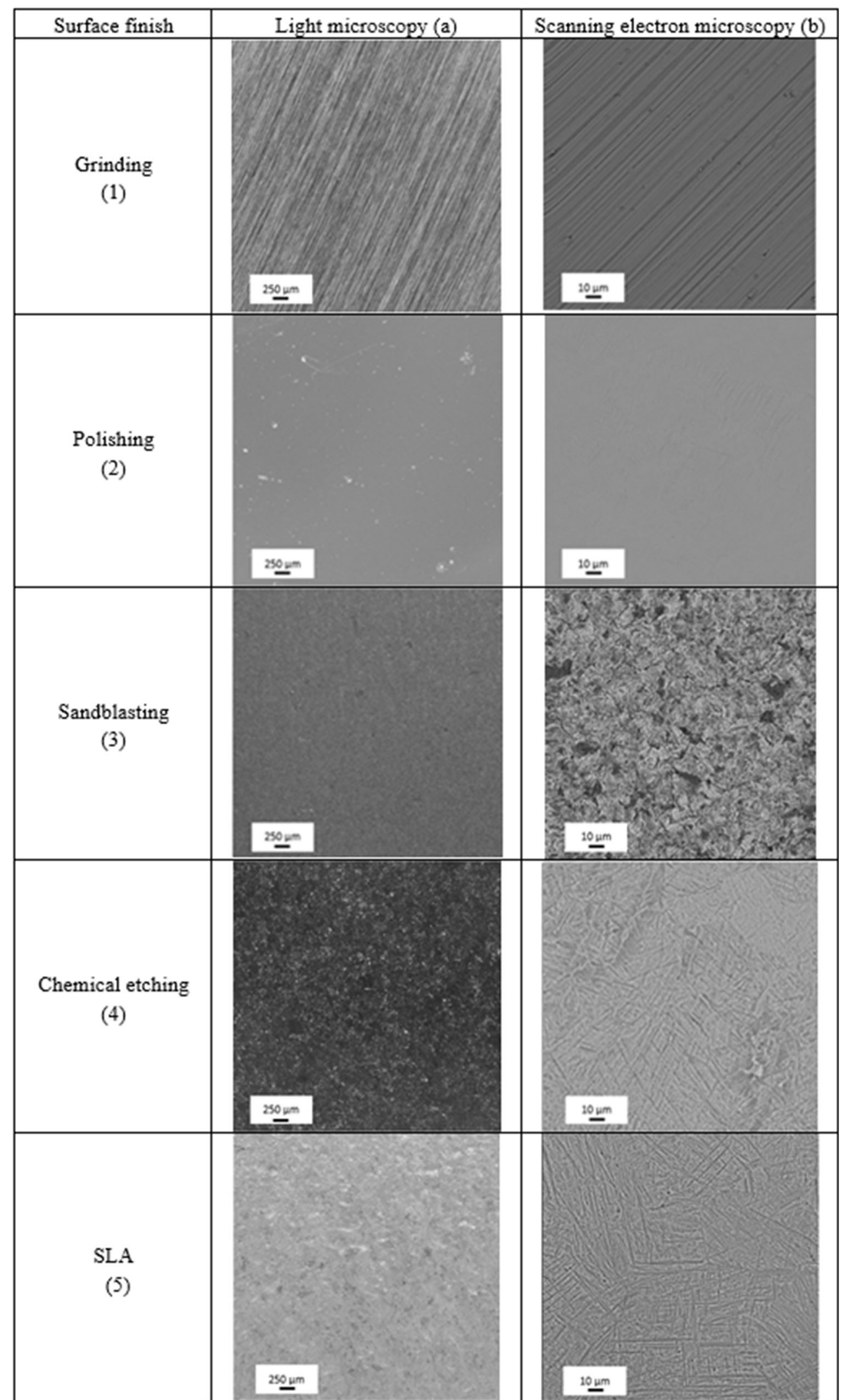


$S_{z}=177.83 \mu \mathrm{m}$ and $S_{z}=151.01 \mu \mathrm{m}$, respectively. The same trends in terms of the highest, intermediate, and lowest values of $S_{z}, S_{a}$ and $S_{q}$ in relation to $R_{z}, R_{a}$ and $R_{q}$ are observed for the surface parameters, which is confirmed by the fact that the tested surfaces in both directions of the plane on which the measurement was carried out behave similarly.

A study with the use of volumetric parameters was also carried out. For this purpose, a section of a threedimensional model with a specific area was used, defined as the reference native area hereinafter referred as the area, on which the real surface area was created, which determines the real surface development. To determine the level of surface development in relation to the reference, a quotient was used in which the ratio of surface area to the reference area was taken into account (Fig. 4).

The smallest surface development is characteristic of surfaces after grinding and polishing-the surface development is negligible at level 1 . In the case of two surfaces, the highest value of the coefficient was observed, which oscillates around 3. For the surface after chemical etching, the quotient was observed, which is $3.18 \pm 0.16$, and for the surface after sandblasting, the quotient is $3.04 \pm 0.4$. A slightly lower quotient is for the SLA area, which is $2.49 \pm 0.21$. It should be remembered that the device used a laser beam, which penetrates the material quite deeply to obtain optical cross sections of the tested surface.

Computed tomography made it possible to obtain three-dimensional surfaces corresponding to the real surface topography. On the surface images, after various surface modifications, there are noticeable irregularities corresponding to the nature of the surface treatment (Fig. 5). The surfaces after polishing and grinding are characterized by the smallest variation in geometry, apart from the edge phenomena occurring at the ends of the sample. Samples after treatment with $\mathrm{Al}_{2} \mathrm{O}_{3}$ abrasive-after sandblasting, and SLA method are characterized by the presence of numerous craters and cavities on the sample surface. The sample after chemical etching shows irregular treatment over the entire surface, due to the presence of areas significantly different in height from the others.

Analyzing the surface deviation, it can be observed that surfaces after polishing and grinding are characterized by low deviations with relatively large surfaces compared to the reference surface related to other surface treatments (Fig. 6). The surfaces after chemical etching and SLA are characterized by a similar course of the deviation curve-on a small area, large fluctuations occur in height ranging from -0.075 to $0.0125 \mathrm{~mm}$. The extension of the tail to the left and the fluctuations of the curve around specific values, with essential participation of craters and depressions on these surfaces. In turn, the curve corresponding to the deviations on the surface after sandblasting is clearly shifted to the right in favor of higher values, which indicates the presence of elevation on the surface.

The measure of the level of development of an area is the ratio of the real area to the nominal area it occupies, and this parameter is called the reference area ratio (Fig. 7). The highest coefficient is characteristic for surfaces after sandblasting and SLA treatment, proving the highest level of surface expansion.

\section{Wettability}

Results of the wettability test regarding the analyzed structures are presented in the following (Fig. 8). The surfaces after grinding, polishing, chemical etching, and acid etching were of hydrophilic properties (contact angle $<90^{\circ}$ ). The values of water contact angle for the mentioned surfaces were $50.7^{\circ} \pm 2.8^{\circ}$, $44.5^{\circ} \pm 4.7^{\circ}, 41.5^{\circ} \pm 5.8^{\circ}$, and $24.7^{\circ} \pm 6.6^{\circ}$, respectively. The surface after sandblasting displayed a hydrophobic effect. (The contact angle with water was calculated to be $90.7^{\circ} \pm 5.3^{\circ}$.) In turn, only these surfaces were characterized by a hydrophobic surface with a water contact angle of more than $90^{\circ}$.

\section{XPS}

The surfaces after five different chemical modifications were characterized using photoelectron spectroscopy. Data obtained from XPS made it possible to obtain an induction of the investigated chemical structure of the titanium alloy surface layer after chemical and physical modifications. Figure 9 shows the widescan surface after grinding, polishing, sandblasting, chemical etching, and SLA treatment. Due to the rough material of the substrate, reflections from $\mathrm{Ti}$ [45-47], $\mathrm{Nb}$, and $\mathrm{Zr}[48,49]$ can be clearly observed. Reflections from other elements, such as C, $\mathrm{O}, \mathrm{F}$, or $\mathrm{Al}$ [50], are also observed on the widescan.

Thanks to the high-resolution spectra, more detailed information about the so-called chemical 

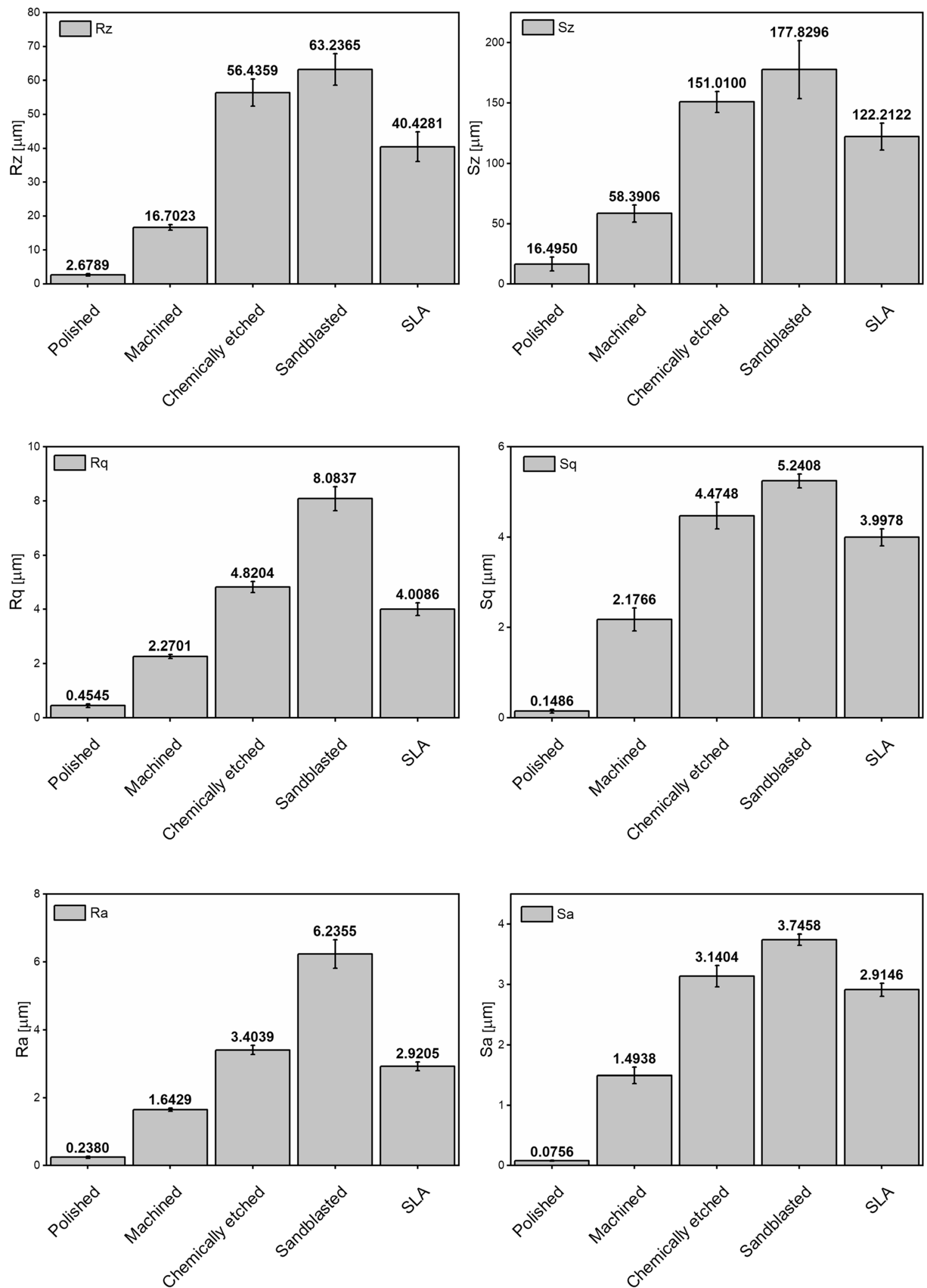

Figure 3 Variability of linear parameters of surface roughness for the parameters $R_{z}, R_{q}$, and $R_{a}$ (left column) and for the parameters $S_{z}$, $S_{q}$, and $S_{a}$ (right column) for surfaces after grinding, polishing chemical etching, sandblasting, and SLA. 
shift can be obtained. This slight change in binding energy (BE) is related to the oxidation state, to the nature of the chemical bonds, and the presence of various adjacent atoms. First of all, carbon reflections can be seen on all surfaces. The detailed spectrum for

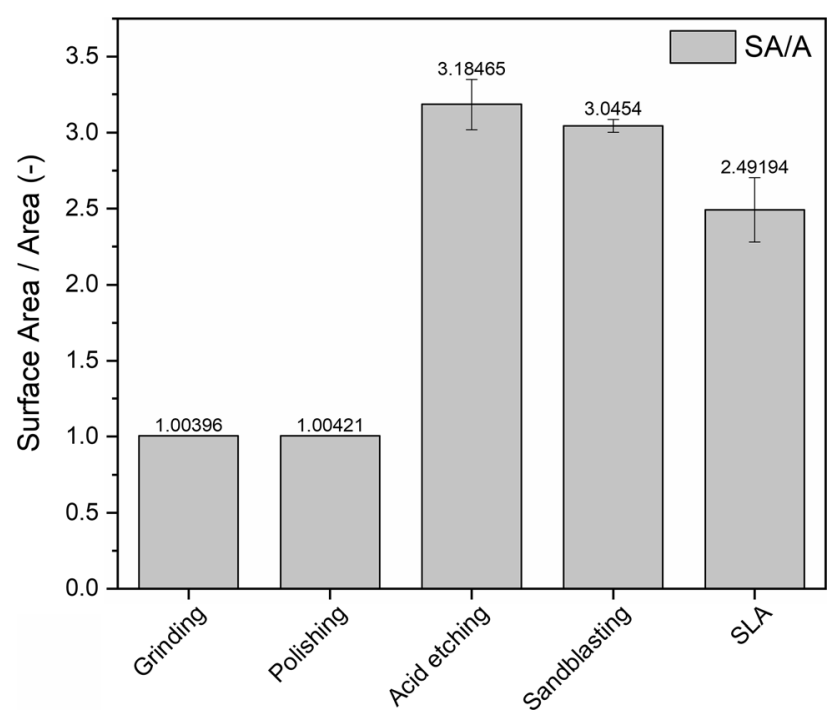

Figure 4 A measure of the development of an area as the ratio of the real area (surface area) to the nominal area (area) of the examined surfaces.
$\mathrm{C}$ is rather characteristic of the so-called random carbon (although it has a large fraction of highly oxidized groups). The main signal can be assigned to $\mathrm{C}-\mathrm{C}$ and $\mathrm{C}-\mathrm{H} \sim 285 \mathrm{eV}$; however, there are also signals indicating the presence of $\mathrm{C}-\mathrm{O}(\sim 287 \mathrm{eV})$, $\mathrm{C}=\mathrm{O}(\sim 289 \mathrm{eV})$ and $\mathrm{O}-\mathrm{C}=\mathrm{O}(\sim 290 \mathrm{eV})$.

Ti $2 \mathrm{p}_{3 / 2}$ peak was observed at $\sim 459 \mathrm{eV}$ and corresponded to the binding energy of $\mathrm{Ti} 2 \mathrm{p}_{3 / 2}$ peak conformed to that of $\mathrm{Ti}$ in $\mathrm{TiO}_{2}$. Moreover, for the signal from $\mathrm{O} 1 \mathrm{~s}$, for the binding energy of $\sim 530$ $\mathrm{eV}$, the presence of oxide- $-\mathrm{TiO}_{2}$, can be assigned. Further shifted peaks by about $2 \mathrm{eV}$ indicate the presence of $\mathrm{OH}$ - hydroxyl groups (Fig. 10).

In the case of surfaces after polishing (Fig. 11), the presence of oxygen reflection was recorded for $\mathrm{BE} \sim 530 \mathrm{eV}$ and can be assigned again for $\mathrm{TiO}_{2}$. Oxygen analysis would indicate that little water is adsorbed, so in general, the adsorption capacity of this sample may be weaker than that of the others. The problem with oxygen modeling here deepened compared to other samples. The signal is wide, which suggests its complexity.

The sandblasted surface is distinguished by the presence of corundum abrasive reflex on the spectrum-aluminum for $\mathrm{BE} \sim 75 \mathrm{eV}$ (Fig. 12). A single (a)

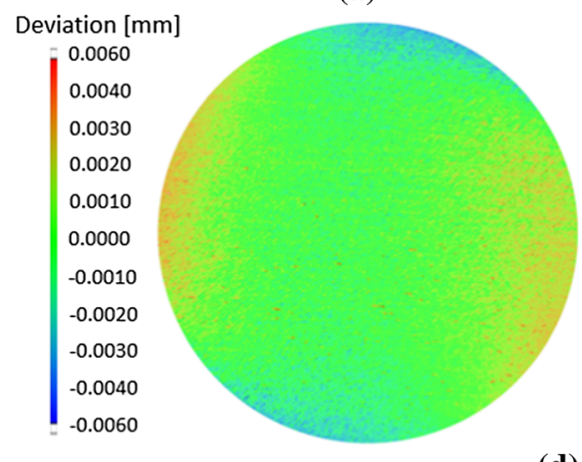

(d)

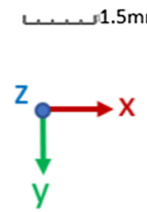

(b)

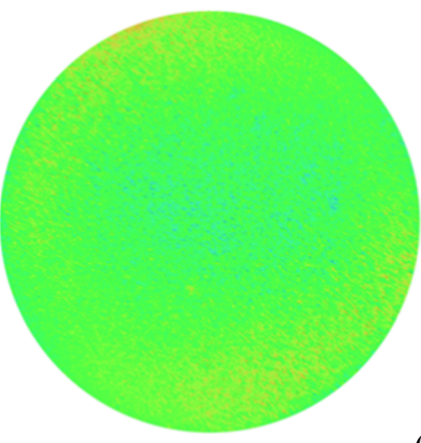

(e)

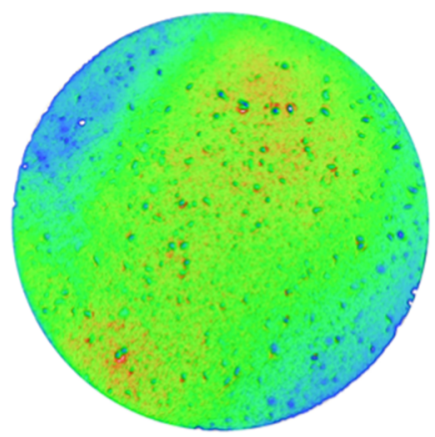

(c)

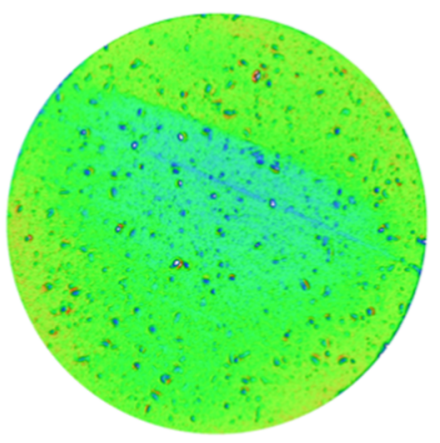

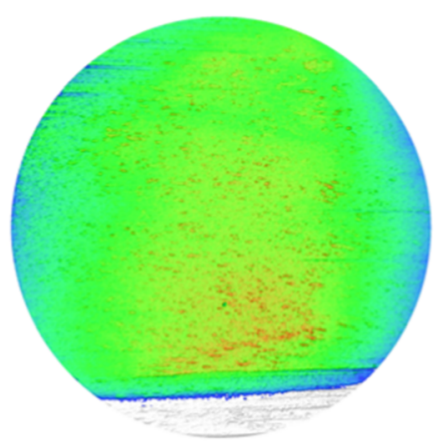

Figure 5 Images of the surface reconstruction obtained using CT with marked deviation.

\section{Springer}



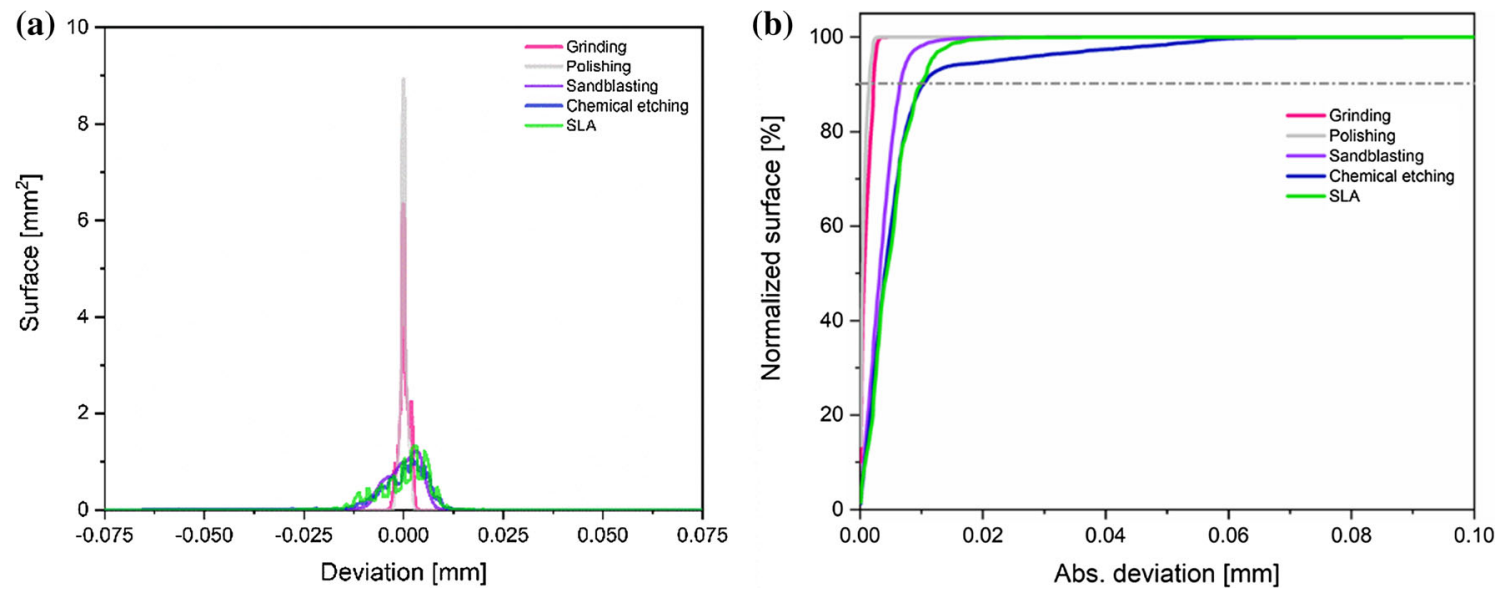

Figure 6 Surface deviation for examined samples.
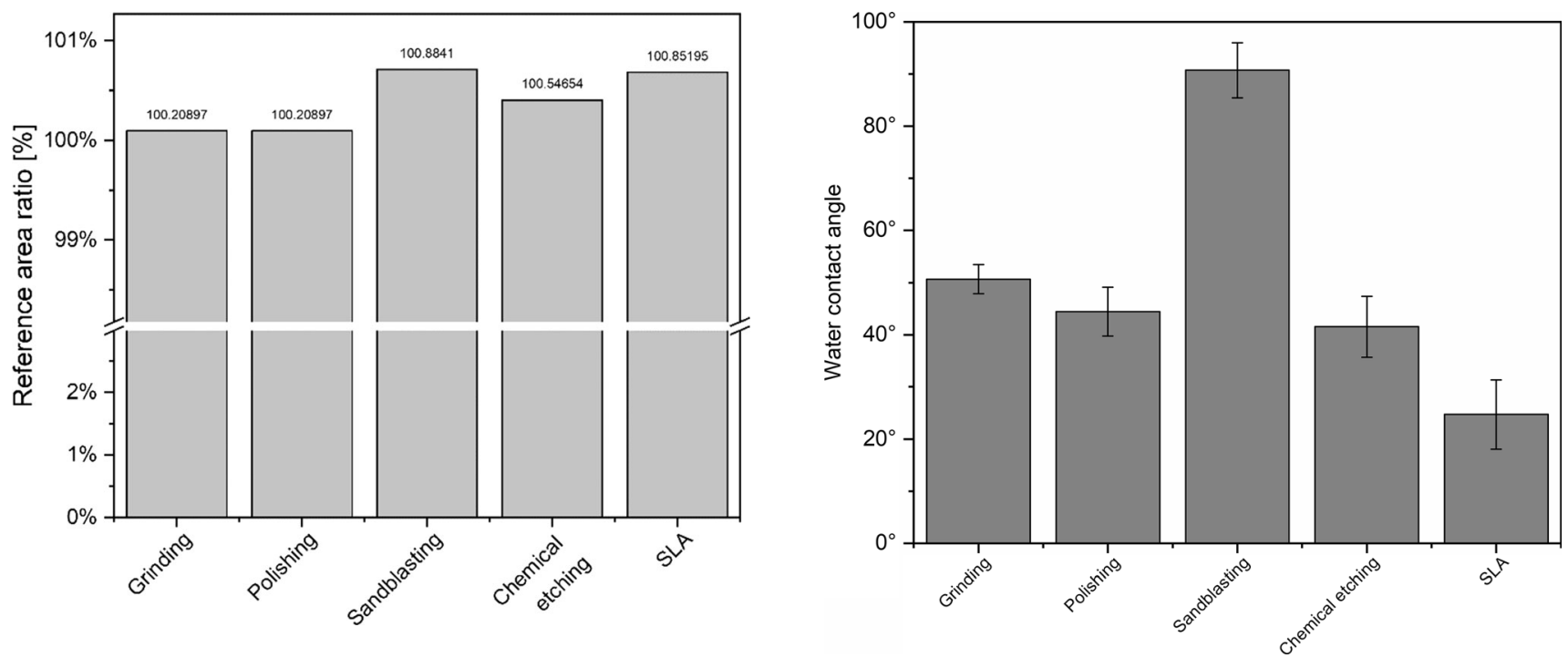

Figure 7 Reference area ratio [\%] obtained from CT data for the examined samples.

peak at this position is characteristic of aluminum in the form of oxide, which is confirmed by the presence of a peak of $\mathrm{O} 1 \mathrm{~s}$ at $\sim 532 \mathrm{eV}$. The aluminum content is significant, so it is probably a combination of titanium and aluminum oxide. Moreover, a peak at $\sim 686 \mathrm{eV}$ can be assigned to $F$.

The deconvolution of the spectra from the surface after the chemical etching (Fig. 13) and SLA (Fig. 14) allowed for the analysis of fluorine $(\sim 685 \mathrm{eV})$ and oxygen which forms $\mathrm{OH}$ - groups $(\sim 532 \mathrm{eV})$ and $\mathrm{H}_{2} \mathrm{O}(\sim 533 \mathrm{eV})$. The presence of fluoride in both cases is due to the use of hydrofluoric acid during both surface modification operations.

Figure 8 Water contact angle of five types of surface with different conditions (grinding, polishing, sandblasting, chemical etching, SLA).

\section{Microbiological tests}

The MTT assay is the most commonly used method to estimate the cell viability and toxicity of a tested compound to the cell culture. Tests using MC3T3 (Fig. 15) and NHDF (Fig. 16) cells have shown that surfaces after various treatments generally show no cytotoxicity. In the case of MC3T3, a negative assay showed a survival rate of $97.33 \%$; regarding the morphological assessment of no endoplasmic reticulum granules, no cell lysis was found. A positive sample showed a survival rate of $50.91 \%$, and in terms of morphological assessment, the cell culture was almost or completely destroyed. Samples after 


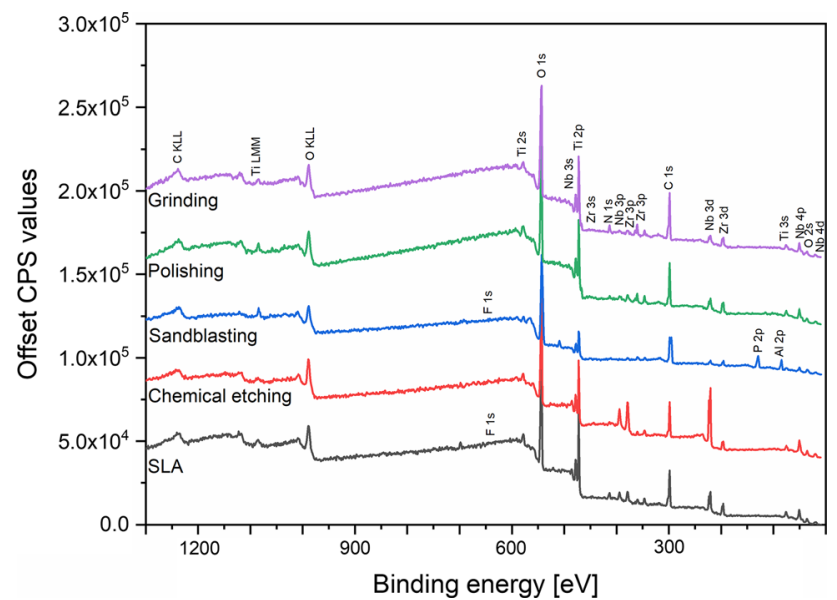

Figure 9 The XPS widescan of samples after grinding, polishing, sandblasting, chemical etching, and SLA.

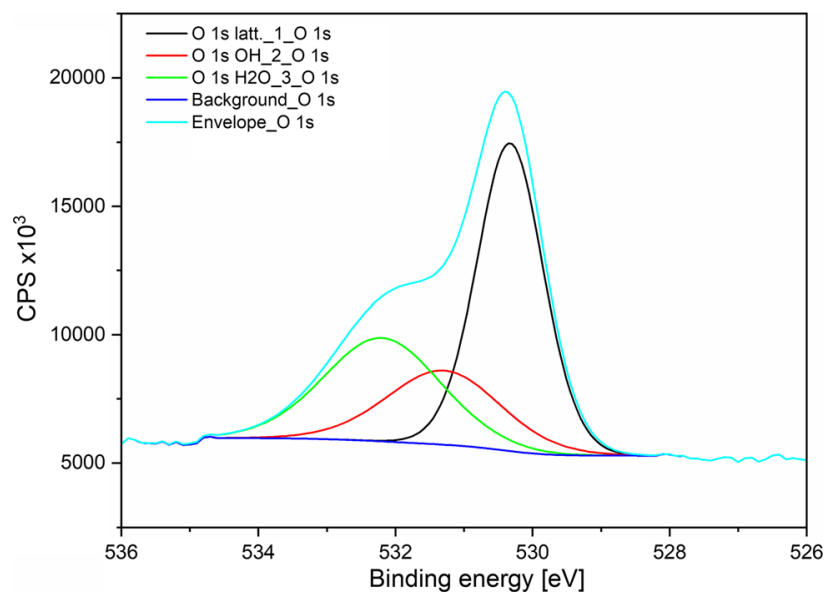

Figure 10 XPS spectrum deconvolution for grinded surface.

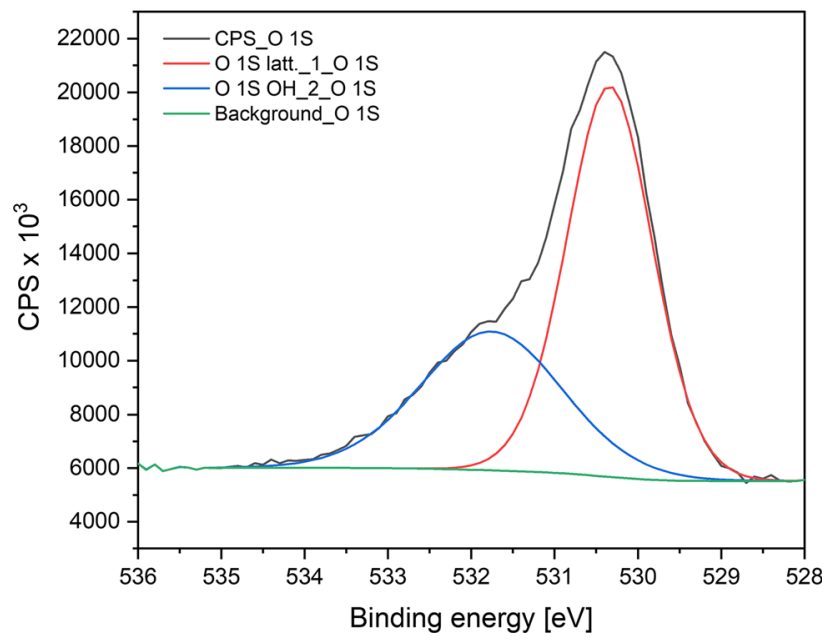

Figure 11 XPS spectrum deconvolution for the polished surface. polishing for the MC3T3 cell line show weak cytotoxicity for $12.5 \%$ and $25 \%$ concentrate, and survival is $92.02 \pm 2.67$ [\%] and $97.96 \pm 5.35$ [\%], respectively. Few endoplasmic reticulum granules and no cell lysis were found regarding morphological changes. Moreover, the culture density was comparable to the negative culture, and there occurred rounded cells (less than 20\%). In case of polished surfaces, for the remaining concentrations (50\% and $100 \%)$, survival was $106.23 \pm 8.87 \quad[\%]$ and $112.13 \pm 6.57 \quad[\%]$, respectively. For the surface after chemical etching, only for $100 \%$ concentrate, a weak cytotoxic effect was observed, for which cell survival was $90.19 \pm 2.88$ [\%], and in the assessment of morphological changes similar as for polished samples. (Endoplasmic reticulum granules and no cell lysis were found, culture density was comparable to negative culture, and rounded cells occurred (less than 20\%).) For the remaining concentrations, no cytotoxic effect was observed, and cell survival for the $50 \%, 25 \%$, and $12.5 \%$ concentrate was $105.57 \pm 7.7 \quad[\%]$, $117.35 \pm 2.77$ [\%], and $122.3 \pm 5.89$ [\%], respectively. No cytotoxic effect on cells was observed on the surfaces after grinding, sandblasting, and SLA treatment. For samples after grinding, cell viability ranged from $111.67 \pm 2.44$ for a 100 concentrate to $128.32 \pm 4.22[\%]$ for a $12.5 \%$ concentrate. Similar values are observed for surfaces after SLA-the lowest survival for $100 \%$ concentrate is $113.77 \pm 4.6$ [\%], and the highest survival for $12.5 \%$ concentrate is $130.12 \pm 4.9$ [\%]. The highest cell survival was observed for sandblasted samples-for $100 \%$ concentrate, it was $123.05 \pm 5.57$ [\%], while for $12.5 \%$ it was $135.86 \pm 7.27[\%]$.

For tests using the NHDF cell line, the survival rate of the negative sample was $98.17 \%$ and the survival of the positive sample was $51.67 \%$. In terms of morphological changes of the positive and negative samples, this is similar to MC3T3. Samples after polishing exhibit a weak cytotoxic effect, and their survival rate is from $71.87 \pm 2.31$ for 100 concentration of extract to $92.71 \pm 1.26$ [\%] for $12.5 \%$ concentration of extract. The following morphological changes in cell structure were observed: Few endoplasmic reticulum granules and no cell lysis were found, culture density was comparable to negative culture, and rounded cells are visible (less than 20\%). In the case of surface after grinding, sandblasting, chemical etching, and SLA treatment, none of these modifications caused a cytotoxic effect on NHDF 

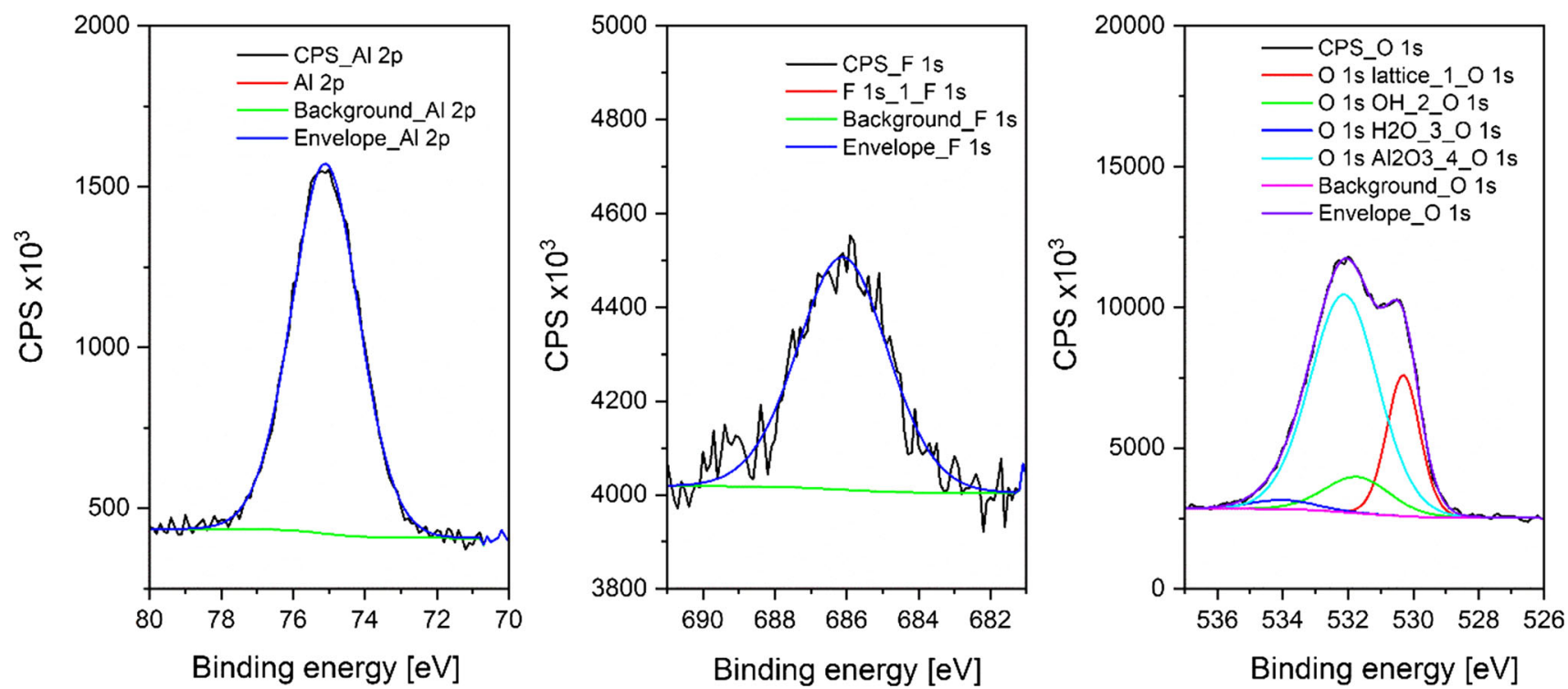

Figure 12 XPS spectrum deconvolution for sandblasted surface.
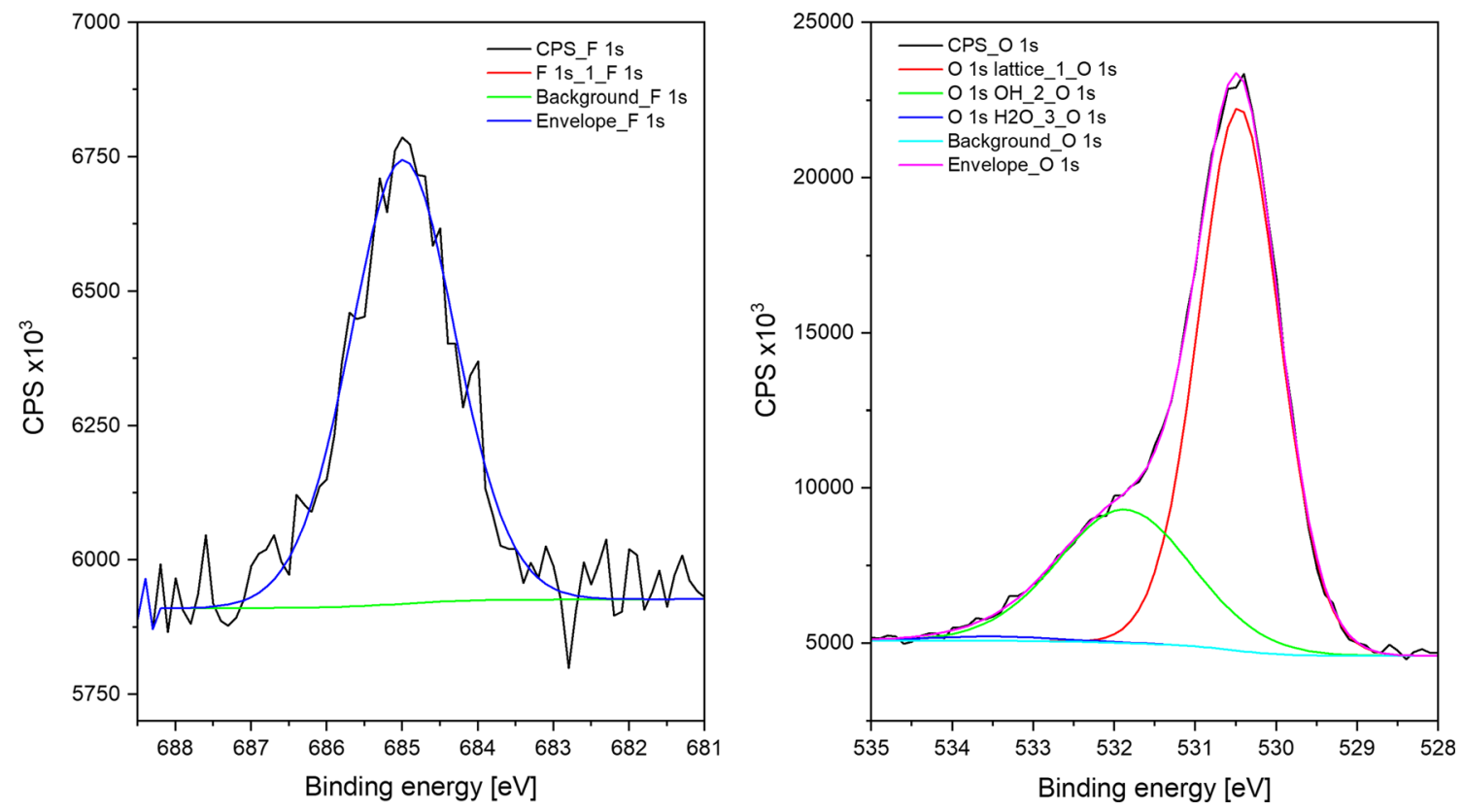

Figure 13 XPS spectrum deconvolution for chemically etched surface.

cells-no endoplasmic reticulum granules and no cell lysis were found and the culture density was comparable to the negative sample. Increased cell survival rate was observed on the surface after SLA modification, and it ranges from $123.88 \pm 1.61$ for a concentration of 100 to $130.17 \pm 4.0$ [\%] for a concentration of $12.5 \%$. In the case of surfaces after grinding, sandblasting, and chemical etching, cell survival is very similar and takes values, respectively, for concentrations from 100 to $12.5 \%$, for surface after grinding from $111.75 \pm 3.04$ to $129.05 \pm 9.08[\%]$, for surfaces after sandblasting from $109.71 \pm 2.94$ to $125.05 \pm 2.93[\%]$, and for surfaces after chemical etching from $106.44 \pm 1.87$ to $149.34 \pm 4.17[\%]$.

Comparing the cell behavior of the two types of assays, the results indicate that surface modification of $\mathrm{Ti}-13 \mathrm{Nb}-13 \mathrm{Zr}$ does not show activity causing a strong reduction of cell viability. 

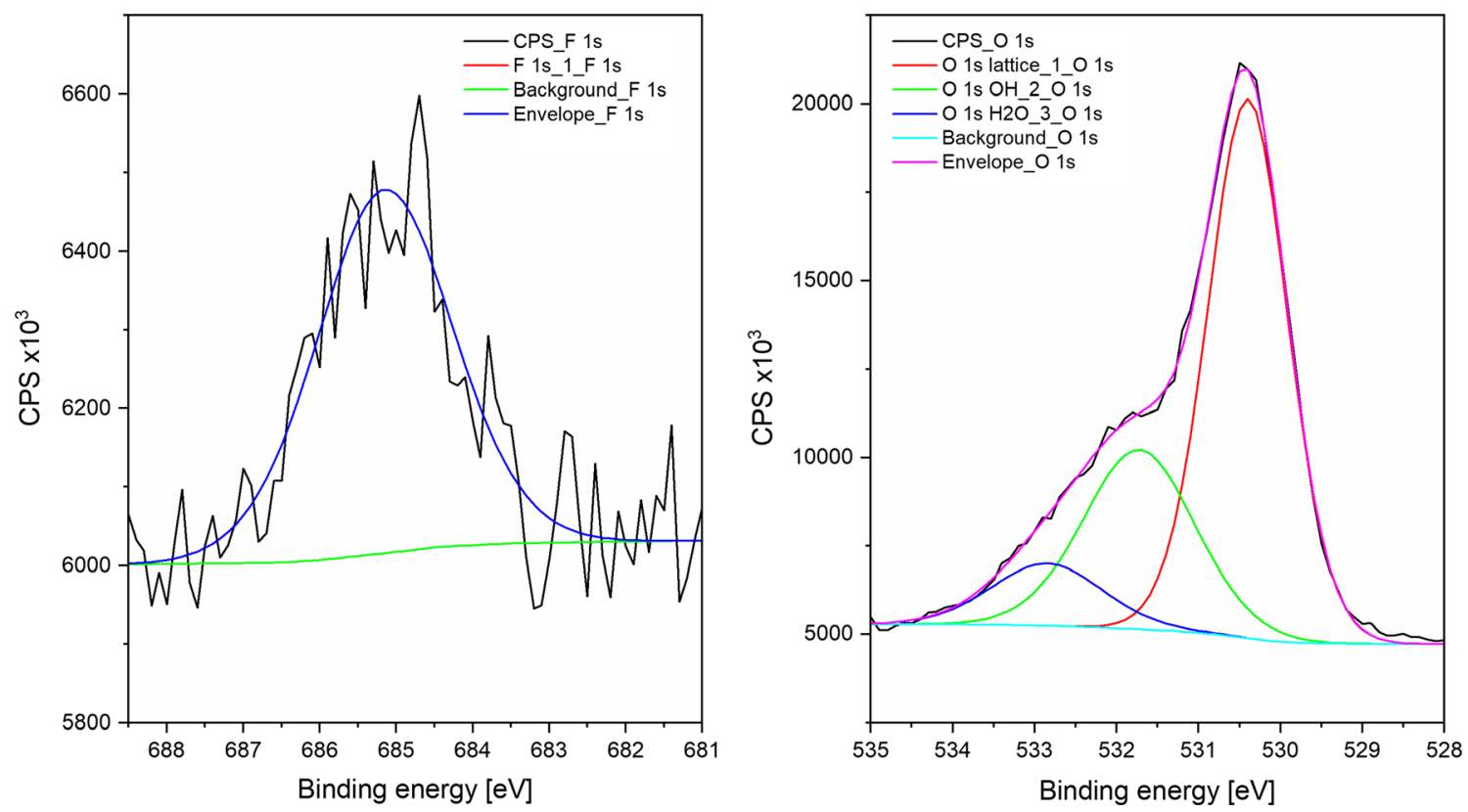

Figure 14 XPS spectrum deconvolution for SLA-ed surface.

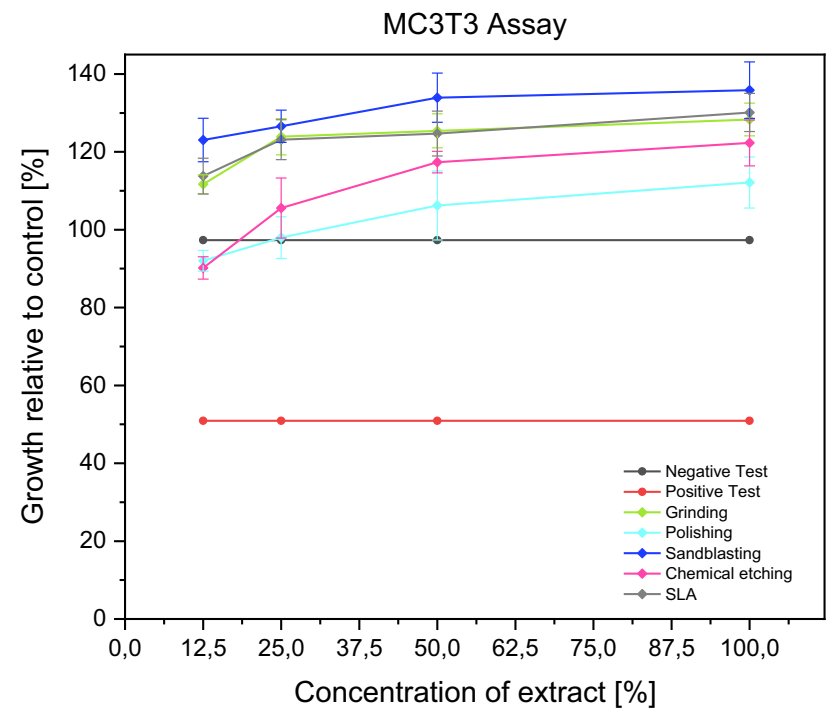

Figure 15 Cytotoxicity test of examined samples after surface modification with the use of MC3T3 assay.

\section{Discussion}

It is common that bone cells have low adhesion to smooth metallic surfaces and the use of such materials can cause inflammation around implants. That is why, surface modifications influencing surface roughness, topography, and chemical composition of the surface are used to increase cell survival rate [51]. The surface properties of macro-roughness, micropits, and cleanness of the $\mathrm{Ti}$ implant are very

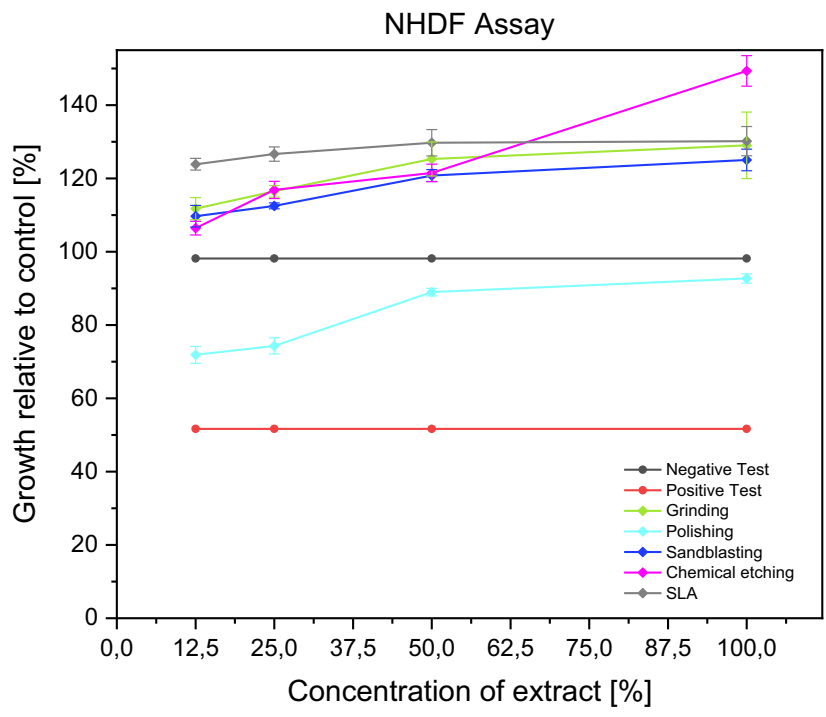

Figure 16 Cytotoxicity test of examined samples after surface modification with the use of NHDF assay.

important for osseointegration. The surface roughness of bone implants improves the stability of bone formation and resorption at the interface between the bone and the implant [52].

There are many titanium surface modification techniques aiming to improve osseointegration. This research focused on five techniques: polishing, grinding, sandblasting, chemical etching, and SLA, all of them influencing the cytotoxic activity of $\mathrm{Ti}-$

\section{Springer}


$13 \mathrm{Nb}-13 \mathrm{Zr}$ medical alloy, due to the different characters of their surface properties.

Surfaces of implants can be divided into categories as follows: smooth $\left(S_{a}<0.5 \mu \mathrm{m}\right)$; minimally rough ( $S_{a}$ between 0.5 and $\left.1.0 \mu \mathrm{m}\right)$; moderately rough $\left(S_{a}\right.$ between 1.0 and $2.0 \mu \mathrm{m})$; and rough $\left(S_{a}>2.0 \mu \mathrm{m}\right)$ [53]. Taking this classification into account, the surfaces after chemical etching, sandblasting, and SLA $\left(S_{a}=3.14,3.65\right.$, and $2.91 \mu \mathrm{m}$, respectively) are considered as rough, the surface after grinding $\left(S_{a-}\right.$ $=1.49 \mu \mathrm{m}$ ) is considered moderately rough, and the surface after polishing $\left(S_{a}=0.08 \mu \mathrm{m}\right)$ is smooth. In the case of SLA surfaces, the nanoporous structure of the acid-etched is applied to a pre-sandblasted microrough structure with a rough and uneven surface consisting of depressions and raised mountainlike areas on the modified surface [51]. The acidetched surfaces were characterized by a number of small craters and groves. The crater walls observed were micropatterned, and pitting was observed at the bottom of the craters. Sandblasted and acid-etched surfaces were significantly rougher than SLA surfaces, which was observed in the case of linear parameters.

The surface topography modifications of titanium implants got interested only after the first 10-20 years of applied experience when clinical thinking was dominated by the concept that titanium implant biocompatibility supported clinical osseointegration with success [54]. The geometric structure of the surface is one of the more important factors determining the quality of a given surface. Roughness parameters refer to specific profile characteristics [55]. Properties of the surface layer of objects may change as a result of the impact of various factors present in the process of their manufacture and operation. The most important of them can be adsorption properties, gas solubility, diffusion properties, and adhesive properties.

Nowadays, surface topography is known as a predominant material property that has been shown to alter material biological responses, and macro-, micro-, and even nano-sized research is conducted. Surface topography can alter subsequent cell attachment, morphology, and migration [56].

Many experimental studies have demonstrated that the implant surface topography influences the bone response in terms of osseointegration rate and bone quality, and the surface modifications on the macro-, micro-, submicro-, and even increasingly popular nano-levels have been put forward. Surface treatments are the most important factors that govern the strength of adhesive joints. The high rough surfaces with so-called macrosized topography are proven to stabilize the implant during the initial phase after implementation, providing enough space for new cell proliferation and bone tissue formulation [57-59]. The microsized topography is obtained by various surface modifications. The study, where different surface preparations of titanium were compared, has shown that grit blasting and subsequent acid etching were capable of enhancing the rapid cellular activity and tissue responses, leading to greater osteogenesis [53, 60]. The role of microtopography is underlined by another research, where the investigated surfaces had $R_{a}$ values in the range of $0.9-0.03 \mu \mathrm{m}$. The rough surfaces $\left(R_{a}=0.87 \mu \mathrm{m}\right)$, prepared by the blasting method, where micrometersized particles of $\mathrm{Al}_{2} \mathrm{O}_{3}$ were used, had much higher levels of osteoblast-like cells attached than smoother ones $\left(R_{a}=0.14 \mu \mathrm{m}\right)$, obtained by the polishing procedure [61]. Within the higher levels of irregularly rough surfaces, values between 1 and $3.9 \mu \mathrm{m}$ are optimal for osseointegration $[62,63]$. The same study reports more precisely a better bone fixation when the average height deviation $\left(S_{a}\right)$ is $1.5 \mu \mathrm{m}$ than $1.2 \mu \mathrm{m}$ for blasted surfaces. On the other hand, a tendency toward more bone in contact and higher removal torques was found for the blasted implant surfaces with an average height deviation $\left(S_{a}\right)$ of $1.2 \mu \mathrm{m}$ than $2.2 \mu \mathrm{m}$. For more recent research of bone response to titanium implants according to surface topography, the conclusions are similar. The examined bone-implant interface of dental implants shows signs of a better osseointegration effect for rough surfaces within the limited extent of $S_{\mathrm{a}}$ between 1 and $2 \mu \mathrm{m}$ [5]. Nevertheless, numerous publications report the average roughness values above $2.5 \mu \mathrm{m}$ to be very successful in clinical applications [64-66]. However, to this day, clinical trials often lack research on implant surface roughness. These studies only provide limited information on topography, showing only $2 \mathrm{D}$ mean roughness $R_{a}$ or $3 \mathrm{D}-S_{a}$ [67].

The physical and mechanical aspects affecting bioadhesion are most often investigated regarding the phenomenon of wettability and mechanical blocking interactions. To deepen our understanding of liquids in contact with the obtained rough surfaces, an evaluation was conducted where water contact angle measurements were made on five types of 
modified surfaces with precisely controlled surface chemistry due to the performed XPS analysis. The low contact angles of acid-etched and SLA-ed specimens $\left(41.5^{\circ} \pm 5.8^{\circ} ; 24.7^{\circ} \pm 6.6^{\circ}\right.$, respectively) can be attributed to their porous surface structure. The low values were investigated to have a better influence on bone attachment and bond creation [68]. Due to the wettability, low contact angles indicate good wetting and the best values of contact angle for cell attachment were assessed at $55^{\circ}$ and for bone regeneration at $35^{\circ}$ to $80^{\circ}$ [68]. These values correspond to the data obtained for all surfaces except the sandblasted ones. The ability of a liquid to wet the surface of a solid is affected by many factors: surface roughness, surface cleanliness, surface energy of the solid relative to the liquid and atmospheric gas, etc. [69]. Hydrophilic surfaces can facilitate the initial interaction between the surface and the wetting fluid, which is important for wound healing and osseointegration [67, 70].

The machined titanium implant surfaces tend to be covered with oxide layers, often with different types of contamination, where chemical treatments are mainly employed to improve the oxide layer thickness required for the passivation of the metal. The chemical composition or charges depend on their bulk composition and surface treatments used and have a critical influence on protein adsorption and cell attachment. The XPS analysis showed the characteristic adsorption of carbon on all analyzed surfaces-this carbon adsorption occurs on every surface open to the atmosphere. The as-machined implant showed no traces of contaminants, as expected (Fig. 5). The $\mathrm{Al}_{2} \mathrm{O}_{3}$ blasted specimen spectrum (Fig. 6) showed contamination with aluminum, also identified by SEM, which was associated with the alumina particles from the blasting process [57]. The literature review of the spectroscopic analyses [71-73] shows that the surface oxide consists mainly of $\mathrm{TiO}_{2}$, which is a stable compound, resistant to chemical attack from most substances. Nevertheless, the analyses also detect contaminations, which are various organic types such as hydrocarbons, fatty acids, and silicones, as well as traces of inorganic impurities $(\mathrm{Si}$, $\mathrm{Ca}, \mathrm{S}, \mathrm{Cl}, \mathrm{Fe}$, etc.) [11]. The organic contaminants most likely come from adsorbed molecules, from the air and from cleaning solvents, while the modification processes leave other traces depending on the selected methods.

Generally, acid etching ends up with a thin $<10$ $n m$ surface oxide layer formation, with mainly $\mathrm{TiO}_{2}$ composition, often with etching solution residues, in particular fluorine. Chemical treatments can also lead to hydrogen incorporation in the surface region below the oxide [74]. $\mathrm{TiO}_{2}$ enhances the proliferation and adhesion of osteoblast-like cells [75]. It is closely related to the important role that an insulating oxide surface layer such as $\mathrm{TiO}_{x}$ or $\mathrm{ZrO}_{2}$ plays in enhancing protein adsorption to an implant surface [76], which confirms the excellent properties of the examined $\mathrm{Ti}-$ $13 \mathrm{Nb}-13 \mathrm{Zr}$ alloy in terms of biocompatibility.

Another interesting occurrence, from a surface engineering point of view, is the production of Tiperoxy gels, as an effect of titanium oxide surface interaction with hydrogen peroxide, $\mathrm{H}_{2} \mathrm{O}_{2}$, that has been suggested to be responsible for titanium biocompatibility [77]. Using hydrogen peroxide in our research during chemical etching shows promising results for the application of $\mathrm{Ti}-13 \mathrm{Nb}-13 \mathrm{Zr}$ surfacemodified alloy in implantology. The produced $\mathrm{O}_{2}$ and $\mathrm{OH}$ can alter the permeability of a surface, e.g., of the Staphylococcus aureus cell membrane [78], which may result in the surface antimicrobial properties desired in implants $[79,80]$. It is worth paying attention to this issue and developing it in terms of the antibacterial properties of $\mathrm{Ti}-13 \mathrm{Nb}-13 \mathrm{Zr}$ surfaces after various types of modifications.

In the case of occurrence of fluorine on some specific surfaces, described in this study, e.g., SLA-ed surface, fluorine is considered a stimulator of metabolism and bone restructuration [74, 81]. This microelement is also responsible for antibacterial properties and prevents the growth of biofilm on the implant surface [82].

It is recognized that commercially pure $\mathrm{Ti}$ shows better cell viability in MTT tests compared to Ti-6Al$4 \mathrm{~V}[83,84]$. The lower cell viability in $\mathrm{Ti}-6 \mathrm{Al}-4 \mathrm{~V}$ is due to the presence of aluminum and vanadium in the alloy. Referring to this information, it is worth mentioning the tested $\mathrm{Ti}-13 \mathrm{Nb}-13 \mathrm{Zr}$ alloy, which showed no clear cytotoxicity in any of the analyzed surface modification cases. It can be compared with the results of other scientists that used Ti-6Al-4V alloy, which was subjected to grinding, and it was observed that cell survival was the highest for surface roughness $\sim R_{a}=0.2 \mu \mathrm{m}$ and $\sim R_{z}=2.0 \mu \mathrm{m}$ [85]. However, it should be taken into account that this alloy contains toxic elements and the use of nontoxic titanium alloys is a much better solution. The results seem to be convergent, and the benefits of using $\mathrm{Ti}-$ $13 \mathrm{Nb}-13 \mathrm{Zr}$ are unquestionable. Analyzing the 
obtained results, it can be determined that cytotoxicity, manifested by inhibition of the metabolic activity and proliferation of cells as well as the induction of their apoptosis and necrosis, was significantly reduced by oxide formation as a result of chemical etching.

\section{Conclusions}

One of the key questions in the study of biomaterials is the relationship between material surface properties and biological reactions. Analysis methods of surface modification are valuable research tools to understand how the structural and chemical properties of surfaces influence material-biosystem interactions. The surface condition has a significant impact on the performance of the implant, and surface modifications are crucial due to the fact that biological tissues only interact through the outer layer.

The results of the conducted research not only confirm the literature reports but also supplement them with phenomena that have not been sufficiently studied, summarizing:

- Microscopic observations in conjunction with surface development studies allowed the evaluation of the overall surface topography of the Ti$13 \mathrm{Nb}-13 \mathrm{Zr}$ alloy after five different surface treatments and a detailed analysis of these data regarding the surface chemical composition and overall cytotoxicity of these surfaces.

- Surface treatment increasing the specific surface area will contribute to faster osseointegration, as evidenced by the increased surface area of possible contact of eukaryotic cells with the implant. In the case of the tested surfaces, they include the surface after chemical etching and the surface after SLA.

- Despite the well-developed surface after sandblasting, this surface is characterized by the presence of abrasive particles, namely toxic $\mathrm{Al}$, as verified in the XPS spectrum. Moreover, due to the possible hydrophobic properties of the surface after sandblasting, preventing the attachment of cells, this type of treatment is not a promising method from the point of view of its applications in implantology.
- The general results obtained from the research indicate high biocompatibility of the examined surfaces after surface modification processes of the investigated titanium alloy $\mathrm{Ti}-13 \mathrm{Nb}-13 \mathrm{Zr}$. The surfaces that support the highest growth of MC3T3 and NHDF cells are the surfaces that underwent chemical treatment, i.e., after chemical etching and SLA treatment. This behavior of cells is directly influenced by the fact that chemical treatment may result in the presence of fluorine and the increase of the oxygen content on the Ti$13 \mathrm{Nb}-13 \mathrm{Zr}$ alloy surface. As is well known, titanium oxide is a highly biocompatible compound, contributing to the strong growth of these eukaryotic cells. In turn, the presence of fluoride on the surface creates favorable conditions for cell growth, supports the cell-attaching capabilities, and stimulates metabolism and bone reconstruction.

Different surface modification techniques were tested to obtain titanium surfaces with better biological properties. Implants made from the new generation of titanium alloy, not containing toxic elements, with the use of surface modification, could be an essential innovation in implantology.

\section{Funding}

This research was funded by the National Centre for Research and Development within the InterDOK POWR.03.02.00-00-I003/16 project concerning interdisciplinary doctoral theses.

\section{Declarations}

Conflict of interest The authors have no financial or proprietary interest in any material discussed in this article.

Ethical approval This article does not contain any studies with human participants or animals performed by any of the authors.

Open Access This article is licensed under a Creative Commons Attribution 4.0 International License, which permits use, sharing, adaptation, distribution and reproduction in any medium or format, as long as you give appropriate credit to the original 
author(s) and the source, provide a link to the Creative Commons licence, and indicate if changes were made. The images or other third party material in this article are included in the article's Creative Commons licence, unless indicated otherwise in a credit line to the material. If material is not included in the article's Creative Commons licence and your intended use is not permitted by statutory regulation or exceeds the permitted use, you will need to obtain permission directly from the copyright holder. To view a copy of this licence, visit http://creativecommons.org/licen ses/by $/ 4.0 /$.

\section{References}

[1] Davidson JA, Kovacs P, (1992) Biocompatible low modulus titanium alloy for medical implants, US005169597A

[2] Thakral GK, Thakral R, Sharma N, Seth J, Vashisht P (2014) Nanosurface-the future of implants. J Clin Diagnostic Res 8:7-10. https://doi.org/10.7860/JCDR/2014/8764.4355

[3] Piattelli M, Scarano A, Paolantonio M, Iezzi G (2002) Petrone, bone response to machined and implantan experimental in study in rabbits. J Oral Implantol 28:2-8

[4] Yang G-L, He F-M, Yang X-F, Wang X-X, Zhao S-F (2008) Bone responses to titanium implants surface-roughened by sandblasted and double etched treatments in a rabbit model. Oral Surg Oral Med Oral Pathol Oral Radiol Endodontol 106:516-524. https://doi.org/10.1016/j.tripleo.2008.03.017

[5] Wennerberg A, Albrektsson T (2009) Effects of titanium surface topography on bone integration: a systematic review. Clin Oral Implants Res 20:172-184. https://doi.org/10.1111/ j.1600-0501.2009.01775.x

[6] Aljateeli M, Wang HL (2013) Implant microdesigns and their impact on osseointegration. Implant Dent 22:127-132. https://doi.org/10.1097/ID.0b013e318278a90b

[7] Khorasani AM, Goldberg M, Doeven EH, Littlefair G (2015) Titanium in biomedical applications-Properties and fabrication: a review. J Biomater Tissue Eng 5:593-619. https://d oi.org/10.1166/jbt.2015.1361

[8] Le Guéhennec L, Soueidan A, Layrolle P, Amouriq Y (2007) Surface treatments of titanium dental implants for rapid osseointegration. Dent Mater 23:844-854. https://doi.org/10. 1016/j.dental.2006.06.025

[9] Bagno A, Di Bello C (2004) Surface treatments and roughness properties of Ti-based biomaterials. J Mater Sci Mater Med 15:935-949. https://doi.org/10.1023/B:JMSM.000004 2679.28493.7f

[10] Quirynen M, Bollen CML (1995) The influence of surface roughness and surface-free energy on supra- and subgingival plaque formation in man: a review of the literature. J Clin Periodontol 22:1-14. https://doi.org/10.1111/j.1600-051X.1 995.tb01765.x

[11] Lausmaa J (2001) Mechanical, thermal, chemical and electrochemical surface treatment of titanium. In: Brunette DM, Tengvall P, Textor M, Thomsen P (eds) Titanium in medicine. Springer, Heidelberg

[12] Suzuki K, Aoki K, Ohya K (1997) Effects of surface roughness of titanium implants on bone remodeling activity of femur in rabbits. Bone 21:507-514. https://doi.org/10.10 16/S8756-3282(97)00204-4

[13] Xue T, Attarilar S, Liu S, Liu J, Song X, Li L, Zhao B, Tang Y (2020) Surface modification techniques of titanium and its alloys to functionally optimize their biomedical properties: thematic review. Front Bioeng Biotechnol 8:1-19. https://d oi.org/10.3389/fbioe.2020.603072

[14] Burnat B, Parchanska-Kowalik M, Klimek L (2014) The influence of chemical surface treatment on the corrosion resistance of titanium castings used in dental prosthetics. Arch Foundry Eng 14:11-16. https://doi.org/10.2478/afe-20 14-0052

[15] Klokkevold PR, Nishimura RD, Adachi M, Caputo A (1997) Osseointegration enhanced by chemical etching of the titanium surface: a torque removal study in the rabbit. Clin Oral Implants Res 8:442-447. https://doi.org/10.1034/j.1600-050 1.1997.080601.x

[16] Elias CN, Oshida Y, Lima JHC, Muller CA (2008) Relationship between surface properties (roughness, wettability and morphology) of titanium and dental implant removal torque. J Mech Behav Biomed Mater 1:234-242. https://doi. org/10.1016/j.jmbbm.2007.12.002

[17] Nádai L, Katona B, Bognár E (2015) Chemical etching of dental implant material. Mater Sci Forum 812:201-206

[18] Nádai L, Katona B, Terdik A, Bognár E (2013) Creative commons attribution chemical etching of titanium samples. Mech Eng 57:53-57. https://doi.org/10.3311/PPme.7046

[19] Leinenbach C, Eifler D (2006) Fatigue and cyclic deformation behaviour of surface-modified titanium alloys in simulated physiological media. Biomaterials 27:1200-1208. h ttps://doi.org/10.1016/j.biomaterials.2005.08.012

[20] Buser D, Broggini N, Wieland M, Schenk RK, Denzer AJ, Cochran DL, Hoffmann B, Lussi A, Steinemann SG (2004) Enhanced bone apposition to a chemically modified SLA titanium surface. J Dent Res 83:529-533. https://doi.org/10. 1177/154405910408300704

[21] Wennerberg A, Albrektsson T, Lausmaa J (1996) Torque and histomorphometric evaluation of c.p. titanium screws blasted with 25- and 75- $\mu \mathrm{m}$-sized particles of Al2O3. J Biomed Mater Res 30:251-260 
[22] Buser D, Nydegger T, Oxland T, Cochran DL, Schenk RK, Hirt HP, Snétivy D, Nolte LP (1999) Interface shear strength of titanium implants with a sandblasted and acid-etched surface: a biomechanical study in the maxilla of miniature pigs. J Biomed Mater Res 45:75-83. https://doi.org/10.1002/ (SICI)1097-4636(199905)45:2\%3c75::AID-JBM1\%3e3.0.C O;2-P

[23] Yuda AW, Supriadi S, Saragih AS, Kim H, Choi SH, Ryu JJ, Koh SY, Park JH, Lee IS (2008) The biocompatibility of SLA-treated titanium implants. AIP Conf Proc 3:25011. h ttps://doi.org/10.1088/1748-6041/3/2/025011

[24] Sader MS, Balduino A, De Almeida Soares G, Borojevic R (2005) Effect of three distinct treatments of titanium surface on osteoblast attachment, proliferation, and differentiation. Clin Oral Implants Res 16:667-675. https://doi.org/10.1111/ j.1600-0501.2005.01135.x

[25] Jung SC, Lee K, Kim BH (2012) Biocompatibility of plasma polymerized sandblasted large grit and acid titanium surface. Thin Solid Films 521:150-154. https://doi.org/10.1016/j.tsf. 2011.12.089

[26] Khodaei M, Valanezhad A, Watanabe I, Yousefi R (2017) Surface and mechanical properties of modified porous titanium scaffold. Surf Coat Technol 315:61-66. https://doi.org/ 10.1016/j.surfcoat.2017.02.032

[27] Li S, Ni J, Liu X, Zhang X, Yin S, Rong M, Guo Z, Zhou L (2012) Surface characteristics and biocompatibility of sandblasted and acid-etched titanium surface modified by ultraviolet irradiation: an in vitro study. J Biomed Mater Res Part B Appl Biomater 100B:1587-1598. https://doi.org/10. 1002/jbm.b.32727

[28] Kim H, Choi SH, Ryu JJ, Koh SY, Park JH, Lee IS (2008) The biocompatibility of SLA-treated titanium implants. Biomed Mater 3:25011. https://doi.org/10.1088/1748-6041/ 3/2/025011

[29] Khanlou HM, Ang BC, Barzani MM, Silakhori M, Talebian S (2015) Prediction and characterization of surface roughness using sandblasting and acid etching process on new non-toxic titanium biomaterial: adaptive-network-based fuzzy inference system. Neural Comput Appl 26:1751-1761. https://doi.org/10.1007/s00521-015-1833-z

[30] Proskurovsky DI, Ozur GE, Rotshtein VP (2000) Production and application of low-energy, high-current electron beams. IEEE Int Conf Plasma Sci. https://doi.org/10.1109/plasma. 2000.855169

[31] Proskurovsky DI, Rotshtein VP, Ozur GE, Markov AB, Nazarov DS, Shulov VA, Ivanov YF, Buchheit RG (1998) Pulsed electron-beam technology for surface modification of metallic materials. J Vac Sci Technol A Vac Surf Film 16:2480-2488. https://doi.org/10.1116/1.581369
[32] Liao TT, Zhang TF, Li SS, Deng QY, Wu BJ, Zhang YZ, Zhou YJ, Guo YB, Leng YX, Huang N (2016) Biological responses of diamond-like carbon (DLC) films with different structures in biomedical application. Mater Sci Eng C 69:751-759. https://doi.org/10.1016/j.msec.2016.07.064

[33] Grenadyorov AS, Solovyev AA, Oskomov KV, Onischenko SA, Chernyavskiy AM, Zhulkov MO, Kaichev VV (2020) Modifying the surface of a titanium alloy with an electron beam and a-C:H:SiOx coating deposition to reduce hemolysis in cardiac assist devices. Surf Coat Technol 381:125113. https://doi.org/10.1016/j.surfcoat.2019.125113

[34] Trakhtenberg IS, Rubshtein AP, Makarova EB, Vladimirov AB, Yugov VA, Uemura K (2008) Adhesion and metabolic processes of marrow cells on titanium surface with $\mathrm{CN} 025$ film. Diam Relat Mater 17:888-891. https://doi.org/10.1016/ j.diamond.2007.10.008

[35] Pokrowiecki R, Szaraniec B, Zaleska M, (2014) Recent trends in surface modification of the titanium biomaterials used for endoosseus dental implants New nano-formulations for oral and maxillo-facial implants View project Peripheral ossifying fibroma-case report View project, Eng Biomater 124 https://www.researchgate.net/publication/263412159 (Accessed November 19, 2018).

[36] Park S, Keller JC, Hard tissue replacements 8.1 8.2, 2003.

[37] Stanford CM, Schneider G, Perinpanayagam H, Keller JC, Midura R, (2003) Biomedical implant surface topography and its effects on osteoblast differentiation in vitro, BioImplant Interface Improv Biomater Tissue React 141-164. h ttps://doi.org/10.1201/9780203491430.

[38] Haisch A, Klaring S, Groger A, Gebert C, Sittinger M (2002) A tissue-engineering model for the manufacture of auricularshaped cartilage implants. Eur Arch Otorhinolaryngol 259:316-321. https://doi.org/10.1007/s00405-002-0446-1

[39] John AA, Jaganathan SK, Supriyanto Z, Manikandan A (2016) Surface modification of titanium and its alloys for the enhancement of osseointegration in orthopaedics. Curr Sci 111:1003-1015

[40] Yuan K, Chan Y-J, Kung K-C, Lee T-M (2014) Comparison of osseointegration on various implant surfaces after bacterial contamination and cleaning: a rabbit study. Int $\mathrm{J}$ Oral Maxillofac Implants 29:32-40

[41] Vinken M, Rogiers V (2015) Protocols in in vitro hepatocyte research. Protoc Vitr Hepatocyte Res 1250:1-390. https://d oi.org/10.1007/978-1-4939-2074-7

[42] ISO 25178-2:2012: Geometric product specification (GPS). Surface texture: areal. Part 2: terms, definitions and surface texture parameters, 2012.

[43] ISO 4287:1997, Geometrical product specifications (GPS) - Surface texture: Profile method - Terms, definitions and surface texture parameters, 1997. 
[44] L. Blunt, X. Jiang, 2003 Advanced techniques for assessment surface topography: development of a basis for $3 \mathrm{D}$ surface texture standards "Surfstand," Kogan Page Science, Sterling VA

[45] Diebold U, Madey TE (1996) TiO 2 by XPS. Surf Sci Spectra 4:227-231. https://doi.org/10.1116/1.1247794

[46] Biesinger MC, Lau LWM, Gerson AR, Smart RSC (2010) Resolving surface chemical states in XPS analysis of first row transition metals, oxides and hydroxides: $\mathrm{Sc}, \mathrm{Ti}, \mathrm{V}, \mathrm{Cu}$ and Zn. Appl Surf Sci 257:887-898. https://doi.org/10.1016/ j.apsusc.2010.07.086

[47] Lausmaa J (1996) Surface spectroscopic characterization of titanium implant materials. J Electron Spectros Relat Phenomena 81:343-361. https://doi.org/10.1016/0368-2048 (95)02530-8

[48] Buabthong P, Stasiewicz NB, Mitrovic S, Lewis NS (2017) Vanadium, niobium and tantalum by XPS. Surf Sci Spectra 24:024001. https://doi.org/10.1116/1.4998018

[49] Lakshmi RV, Bera P, Anandan C, Basu BJ (2014) Effect of the size of silica nanoparticles on wettability and surface chemistry of sol-gel superhydrophobic and oleophobic nanocomposite coatings. Appl Surf Sci 320:780-786. http s://doi.org/10.1016/j.apsusc.2014.09.150

[50] Moulder JF, Stickle WF, Sobol PE, Bomben KD (1992) Handbook of X-ray photoelectron spectroscopy: a reference book of standard spectra for identification and interpretation of XPS data. Perkin-Elmer Corporation, Eden Prairie, Minnesota, USA

[51] Velasco-Ortega E, Alfonso-Rodríguez CA, Monsalve-Guil L, España-López A, Jiménez-Guerra A, Garzón I, Alaminos M, Gil FJ (2016) Relevant aspects in the surface properties in titanium dental implants for the cellular viability. Mater Sci Eng C 64:1-10. https://doi.org/10.1016/j.msec.2016.03. 049

[52] Jemat A, Ghazali MJ, Razali M, Otsuka Y (2015) Surface modifications and their effects on titanium dental implants. Biomed Res Int 2015:1-11. https://doi.org/10.1155/2015/ 791725

[53] T. Albrektsson, A. Wennerberg, (2004) Oral implant surfaces: Part 1-review focusing on topographic and chemical properties of different surfaces and in vivo responses to them, Int J Prosthodont 17:536-543. http://europepmc.org/ abstract/MED/15543910.

[54] Mendonça G, Mendonça DBS, Aragão FJL, Cooper LF (2008) Advancing dental implant surface technology-from micron- to nanotopography. Biomaterials 29:3822-3835. h ttps://doi.org/10.1016/j.biomaterials.2008.05.012

[55] L. Yang, Nanotechnology-Enhanced Orthopedic Materials, Nanotechnology-Enhanced Orthop Mater (2015) pp 1-25. h ttps://doi.org/10.1016/b978-0-85709-844-3.00001-x.
[56] P. Sahoo, 1 - Surface topography, in: J.P. Davim (Ed.), Tribol. Eng., Woodhead Publishing, 2011: pp. 1-32. https://doi. org/10.1533/9780857091444.1.

[57] da Silva MHP, Soares GA, Elias CN, Lima JHC, Schechtman H, Gibson IR, Best SM (2000) Surface analysis of titanium dental implants with different topographies. Mater Res 3:61-67. https://doi.org/10.1590/s151614392000000300003

[58] Stanford CM (2008) Surface modifications of dental implants. Aust Dent J 53:S26-S33. https://doi.org/10.1111/j. 1834-7819.2008.00038.x

[59] Alla RK, Ginjupalli K, Upadhya N, Shammas M, Ravi RK, Sekhar R (2011) Surface roughness of implants: a review. Trends Biomater Artif Organs 25:112-118

[60] Albrektsson T, Wennerberg A (2004) Oral implant surfaces: Part 2-review focusing on clinical knowledge of different surfaces. Int J Prosthodont 17:544-564

[61] Wennerberg A (1999) The role of surface roughness for implant incorporation in bone. Cells Mater 9:1-19

[62] Kim I-H, Kwon T-Y, Kim K-H (2015) Wetting behavior of dental implants. Wetting Wettability. https://doi.org/10.5772/ 61098

[63] Bulutsuz AG, Mercan CU, Karapinar G, Katiboğlu AB, Lewandowska M (2016) Estimation of surface modification methods effect on topography of dental implants by using metrological observation techniques. Acta Phys Pol A 129:625-627

[64] Buser D, Janner SFM, Wittneben J-G, Brägger U, Ramseier CA, Salvi GE (2012) 10-year survival and success rates of 511 titanium implants with a sandblasted and acid-etched surface: a retrospective study in 303 partially edentulous patients. Clin Implant Dent Relat Res 14:839-851. https://d oi.org/10.1111/j.1708-8208.2012.00456.x

[65] Chappuis V, Buser R, Brägger U, Bornstein MM, Salvi GE, Buser D (2013) Long-term outcomes of dental implants with a titanium plasma-sprayed surface: a 20 -year prospective case series study in partially edentulous patients. Clin Implant Dent Relat Res 15:780-790. https://doi.org/10.111 1/cid.12056

[66] Levine RA, Sendi P, Bornstein MM (2012) Immediate restoration of nonsubmerged titanium implants with a sandblasted and acid-etched surface: 5-year results of a prospective case series study using clinical and radiographic data. Int J Periodontics Restor Dent 32:39-47

[67] Rupp F, Gittens RA, Scheideler L, Marmur A, Boyan BD, Schwartz Z, Geis-Gerstorfer J (2014) A review on the wettability of dental implant surfaces I: theoretical and experimental aspects. Acta Biomater 10:2894-2906. https://doi. org/10.1016/j.actbio.2014.02.040 
[68] Hintze V, Bierbaum S, Scharnweber D, Implant surface modifications and new development in surface coatings, Elsevier Ltd., 2019. https://doi.org/10.1016/B978-0-08-102 478-2.00005-2

[69] Mahyudin F, Hermawan H (2016) Biomaterials and medical devices-A perspective from an emerging country, https://doi. org/10.1007/978-3-319-14845-8

[70] Rupp F, Scheideler L, Eichler M, Geis-Gerstorfer J (2011) Wetting behavior of dental implants. Int J Oral Maxillofac Implants 26:1256-1266

[71] Lorenzetti M, Dogša I, Stošicki T, Stopar D, Kalin M, Kobe S, Novak S (2015) The influence of surface modification on bacterial adhesion to titanium-based substrates. ACS Appl Mater Interfaces 7:1644-1651. https://doi.org/10.1021/a m507148n

[72] Lorenzetti M, Pellicer E, Sort J, Baró MD, Kovač J, Novak S, Kobe S (2014) Improvement to the corrosion resistance of Ti-based implants using hydrothermally synthesized nanostructured anatase coatings. Materials (Basel) 7:180-194. h ttps://doi.org/10.3390/ma7010180

[73] Zhou L, Yuan T, Tang J, He J, Li R (2019) Mechanical and corrosion behavior of titanium alloys additively manufactured by selective laser melting-A comparison between nearly $\beta$ titanium, $\alpha$ titanium and $\alpha+\beta$ titanium. Opt Laser Technol 119:105625. https://doi.org/10.1016/j.optlastec.201 9.105625

[74] Liu X, Chu PK, Ding C (2004) Surface modification of titanium, titanium alloys, and related materials for biomedical applications. Mater Sci Eng R Rep 47:49-121. https://d oi.org/10.1016/j.mser.2004.11.001

[75] Wang Y, Wen C, Hodgson P, Li Y (2014) Biocompatibility of $\mathrm{TiO} 2$ nanotubes with different topographies. J Biomed Mater Res Part A 102:743-751. https://doi.org/10.1002/jb m.a.34738

[76] F. Namavar, R.F. Sabirianov, D. Marton, A.I. Rubinstein, K.L. Garvin, Why is Titanium Biocompatible?, San Francisco, California, 2012. http://www.ors.org/Transactions/58/ 0981.pdf.

[77] Tengvall P, Lundström I, Sjöqvist L, Elwing H, Bjursten LM (1989) Titanium-hydrogen peroxide interaction: model studies of the influence of the inflammatory response on titanium implants. Biomaterials 10:166-175. https://doi.org/ 10.1016/0142-9612(89)90019-7

[78] Jhong YT, Chao CY, Hung WC, Du JK (2020) Effects of various polishing techniques on the surface characteristics of the Ti-6Al-4V alloy and on bacterial adhesion. Coatings 10:1-23. https://doi.org/10.3390/coatings10111057

[79] Bazaka K, Jacob MV, Crawford RJ, Ivanova EP (2012) Efficient surface modification of biomaterial to prevent biofilm formation and the attachment of microorganisms. Appl Microbiol Biotechnol 95:299-311. https://doi.org/10. 1007/s00253-012-4144-7

[80] Oliveira WF, Silva PMS, Silva RCS, Silva GMM, Machado G, Coelho LCBB, Correia MTS (2018) Staphylococcus aureus and Staphylococcus epidermidis infections on implants. J Hosp Infect 98:111-117. https://doi.org/10.1016/ j.jhin.2017.11.008

[81] Ellingsen JE (1995) Pre-treatment of titanium implants with fluoride improves their retention in bone. J Mater Sci Mater Med 6:749-753. https://doi.org/10.1007/BF00134312

[82] Junka AF, Szymczyk P, Secewicz A, Pawlak A, Smutnicka D, Ziółkowski G, Bartoszewicz M, Chlebus E (2016) The chemical digestion of Ti6Al7Nb scaffolds produced by selective laser melting reduces significantly ability of Pseudomonas aeruginosa to form biofilm. Acta Bioeng Biomech Orig Pap. https://doi.org/10.5277/ABB-00333-2015-01

[83] Chandar S, Kotian R, Madhyastha P, Kabekkodu S, Rao P (2017) In vitro evaluation of cytotoxicity and corrosion behavior of commercially pure titanium and $\mathrm{Ti}-6 \mathrm{Al}-4 \mathrm{~V}$ alloy for dental implants. J Indian Prosthodont Soc 17:35-40. https://doi.org/10.4103/0972-4052.197936

[84] Chen Z, Patwari M, Liu D (2019) Cytotoxicity of orthodontic temporary anchorage devices on human periodontal ligament fibroblasts in vitro. Clin Exp Dent Res 5:648-654. https://doi.org/10.1002/cre2.230

[85] Prochor P, Mierzejewska ZA (2019) Influence of the surface roughness of PEEK GRF30 and Ti6A14V SLM on the viability of primary human osteoblasts determined by the MTT test. Materials (Basel). https://doi.org/10.3390/ma1224189

Publisher's Note Springer Nature remains neutral with regard to jurisdictional claims in published maps and institutional affiliations. 